\title{
Mesoscale Modeling of the Meteorological Impacts of Irrigation during the 2012 Central Plains Drought ${ }^{\circ}$
}

\author{
Clint Aegerter, ${ }^{\mathrm{a}, \mathrm{b}}$ Jun Wang,,${ }^{\mathrm{a}, \mathrm{c}, \mathrm{d}}$ Cui Ge, ${ }^{\mathrm{a}, \mathrm{c}, \mathrm{d}}$ SuAt Irmak, ${ }^{\mathrm{e}}$ Robert OGLesby, ${ }^{\mathrm{a}}$ \\ BRIAN WARDLOW, ${ }^{\mathrm{f} g}$ HAISHUN YANG, ${ }^{\mathrm{h}}$ JINGSHEN YOU, ${ }^{\mathrm{i}}$ AND MARTHA SHULSKI ${ }^{\mathrm{i}}$ \\ ${ }^{a}$ Department of Earth and Atmospheric Sciences, University of Nebraska-Lincoln, Lincoln, Nebraska \\ ${ }^{\mathrm{b}}$ NOAA/National Weather Service/Weather Forecast Office La Crosse, La Crosse, Wisconsin \\ ${ }^{\mathrm{c}}$ Center for Global and Regional Environmental Research, The University of Iowa, Iowa City, Iowa \\ ${ }^{\mathrm{d}}$ Department of Chemical and Biochemical Engineering, The University of Iowa, Iowa City, Iowa \\ ${ }^{\mathrm{e}}$ Department of Biological Systems Engineering, University of Nebraska-Lincoln, Lincoln, Nebraska \\ ${ }^{\mathrm{f}}$ Center for Advanced Land Management Information Technologies, University of Nebraska-Lincoln, Lincoln, Nebraska \\ ${ }^{\mathrm{g}}$ School of Natural Resources, University of Nebraska-Lincoln, Lincoln, Nebraska \\ ${ }^{\mathrm{h}}$ Department of Agronomy and Horticulture, University of Nebraska-Lincoln, Lincoln, Nebraska \\ ${ }^{i}$ Nebraska State Climate Office, School of Natural Resources, University of Nebraska-Lincoln, Lincoln, Nebraska
}

(Manuscript received 30 August 2016, in final form 29 December 2016)

\begin{abstract}
In the summer of 2012, the central plains of the United States experienced one of its most severe droughts on record. This study examines the meteorological impacts of irrigation during this drought through observations and model simulations using the Community Land Model coupled to the Weather Research and Forecasting (WRF) Model. A simple parameterization of irrigation processes is added into the WRF Model. In addition to keeping soil moisture in irrigated areas at a minimum of $50 \%$ of soil moisture hold capacity, this irrigation scheme has the following new features: 1) accurate representation of the spatial distribution of irrigation area in the study domain by using a MODIS-based land surface classification with 250-m pixel size and 2) improved representation of the time series of leaf area index (LAI) values derived from crop modeling and satellite observations in both irrigated and nonirrigated areas. Several numerical sensitivity experiments are conducted. The WRF-simulated temperature field when including soil moisture and LAI modification within the model is shown to be most consistent with ground and satellite observations, all indicating a temperature decrease of $2-3 \mathrm{~K}$ in irrigated areas relative to the control run. Modification of LAI in irrigated and dryland areas led to smaller changes, with a 0.2-K temperature decrease in irrigated areas and up to a $0.5-\mathrm{K}$ temperature increase in dryland areas. Furthermore, the increased soil moisture and modified LAI are shown to lead to statistically significant increases in surface divergence and surface pressure and to decreases in planetary boundary layer height over irrigated areas.
\end{abstract}

\section{Introduction}

The Intergovernmental Panel on Climate Change (IPCC) has identified the effect of land-use and landcover change as one of the largest uncertainties in global climate models (IPCC 2013). Numerous types of landcover changes, such as those related to agriculture, deforestation, and urbanization, have been shown to have an impact on several atmospheric variables, including

Supplemental information related to this paper is available at the Journals Online website: http://dx.doi.org/10.1175/ JAMC-D-16-0292.s1.

Corresponding author: Jun Wang, jun-wang-1@uiowa.edu temperatures, humidity, and precipitation (Mahmood et al. 2014; Pielke et al. 2007). The addition of water to the soil through human activities such as irrigation, which is a common agriculture-related land use, accelerates water cycles in the Earth system, thereby affecting the surface energy budget, regional climate, and crop yield (Adegoke et al. 2003; Evans and Zaitchik 2008). Worldwide, irrigated land area has increased from 40 million ha in 1990 to more than 270 million ha in 2000 and further increased by $11.49 \%$ to 301 million ha in 2010 (Siebert et al. 2005, 2010). The total irrigated land in the United States has also increased in recent years, although more slowly than the global rate, from approximately 22.4 million ha in 2002 to 22.6 million ha in 2012, an increase of $0.89 \%$ (USDA 2004, 2014). In a 
report by Maupin et al. (2014), it is estimated that irrigation accounted for $33 \%$ of the total water pumped in the United States in 2010, amounting to approximately $4.35 \times 10^{8} \mathrm{~m}^{3} \mathrm{day}^{-1}$ (115 billion gallons day $\left.{ }^{-1}\right)$. As irrigation continues to become more prevalent, more water will be introduced into the atmosphere that would otherwise remain either at or under the ground. Hence, it is important to understand how irrigation affects climate at both the regional and global scales.

This study aims to better understand the impacts of irrigation on regional climate in Nebraska during severe drought when irrigation would likely be used most. Irrigation in Nebraska is unique in many ways. Much of Nebraska has access to the Ogallala Aquifer (one of the largest underground aquifers in the world), which currently provides a sufficient amount of water to continue irrigation even during severe drought. When compared with other states in the United States, Nebraska was the seventh nationally in water pumped for irrigation, pumping $2.14 \times 10^{7} \mathrm{~m}^{3} \mathrm{day}^{-1}$ (5.66 billion gallons day ${ }^{-1}$ ) in 2010 , with approximately $76 \%$ being groundwater, which is the 13th highest percentage of all states but the second highest for states in the top 10 of total water pumped for irrigation (Maupin et al. 2014). In comparison with other states, Nebraska has experienced the largest areal increase of irrigated land in the past decade, from approximately 3.1 million ha in 2002 to 3.4 million ha in 2012, an increase of $9.68 \%$, passing California to become the state with the largest total irrigated area (USDA 2004, 2014).

Overall, irrigation brings a large amount of water to the surface-where it can possibly interact with the atmosphere-that would not otherwise be present. In 2012, the year examined in this study, the central plains region of the United States (including Nebraska) experienced its most unprecedented drought since the ground-based data record began in the late 1800s (Hoerling et al. 2014). Therefore, 2012 provides an excellent year in which to study the meteorological impacts of irrigation in $\mathrm{Ne}$ braska, because irrigation would be used in this maximum capacity during a year such as this. The drought, combined with the spatial prevalence and concentration of irrigation in Nebraska, also allows for a fairly unique examination of the "maximum" impacts of irrigation in Nebraska in extreme drought conditions. This paper uses both numerical model output and observation data (satellite and ground based) to study irrigation's impacts on temperature and other atmospheric processes in 2012 in Nebraska. The rest of the paper is organized as follows: Section 2 contains a review of past studies on the impact of irrigation on climate, with a focus on numerical modeling of the impacts, examining differences between this study and previous studies. Section 3 presents the datasets used in this study, and section 4 provides a description of the model and associated sensitivity experiments. Results and model validation are presented in section 5 , and section 6 contains the main conclusions of the study, as well as some ideas for future work.

\section{Background and motivation}

Although the influence of irrigation on regional climate has been examined by many past studies, its effects are still not completely understood, with several (sometimes competing) impacts being illustrated in both observational studies and modeling studies. Early observational studies, as summarized in Sellers (1965) and further demonstrated by Bastable et al. (1993), showed very different diurnal energy budgets between vegetated and bare land surfaces. As documented by numerous recent studies and preliminary observational work, irrigation not only has a cooling effect during crop-growing season in irrigated areas through its modulation of sensible and latent heat flux at the surface but also can affect the regional and seasonal temperature through adding water vapor to the atmosphere and soil. The magnitude of these effects on temperature is found to be significant enough to mask or strengthen the warming effect from carbon dioxide at the regional scale (Adegoke et al. 2003; Bonfils and Lobell 2007; Skaggs and Irmak 2012; Kueppers et al. 2008; Lobell et al. 2008; Mahmood et al. 2004; Raddatz 2007). A modeling study by Sacks et al. (2009) showed that the cooling effect of irrigation in global and annual averages is negligible but can be $0.5 \mathrm{~K}$ in many NorthernHemispheric midlatitude regions. Also using a global model, Puma and Cook (2010) showed that after the expansion of irrigation in North America, Europe, and Asia during the twentieth century, a related cooling effect spread and intensified by the end of this time period. They also found that irrigation lead to boreal winter warming over North America and Asia in the latter part of the last century because of an enhanced greenhouse effect from increased water vapor near the surface. In contrast, Cook et al. (2011) used a global model to study the effects of irrigation for future climate projections under the modern greenhouse gas (GHG) scenario (year 2000) and increased ("A1B") scenario (year 2050), and showed that the extent to which irrigation will continue to "mask" the warming from increased GHG forcing will be influenced by changes in the background evaporative regime, secondary irrigation effects such as clouds and precipitation, and human-related decisions and abilities to maintain (or increase) current irrigation rates.

Indeed, at the continental scale, the effects of irrigation on surface temperature and its secondary effects on clouds, precipitation, and atmospheric dynamics are found to be more significant. Saeed et al. (2009) presented 
an improvement in the simulation of the southern Asian summer monsoon after considering irrigation processes in a regional climate model. Ozdogan et al. (2010) used a land surface model (LSM) with reanalysis and satellite data and showed that irrigation resulted in a $12 \%$ increase in evapotranspiration when averaged over all irrigated areas in the continental United States during the 2003 growing season.

More comprehensive analysis has also been conducted to understand the effects of irrigation on climate at regional scale. Qian et al. (2013) recently showed that consideration of irrigation in the southern plains reduces the bias in surface parameters (moisture, temperature, and fluxes) simulated by the Weather Research and Forecasting (WRF) Model, especially during dry years. They further found an irrigation-induced reduction of lifting condensation level and mixed-layer depth and an increase of shallow clouds, although precipitation is only slightly increased and highly variable in space. Kueppers et al. (2007) showed an average decrease of 3.7 and $7.5 \mathrm{~K}$ for August mean and maximum temperatures, respectively, over a 20-yr (1981-2000) simulation in California in which natural vegetation was converted to irrigated agriculture. Their model also estimated an irrigation-induced overall net temperature decrease of $0.38 \mathrm{~K}$ for California in August. They further showed that this cooling stabilizes the atmosphere and thus reduces the strength of westerly land-sea breeze by $20 \%-40 \%$, although no discernable change in clouds or precipitation was found. Crook (1996) and Pielke (2001) have shown that the irrigation-induced cooling at the surface can lead to increased convective inhibition and, therefore, less convection, although Pielke and Zeng (1989) have shown that convective available potential energy increases over irrigated areas, meaning any convection that does form could perhaps be more vigorous over irrigated areas. The cooling effect is also shown in the modeling work of Lawston et al. (2015), which examines the impacts of different irrigation methods (drip, sprinkler, and two flood methods with varying levels of water-application aggressiveness) on 2-day weather forecasts in dry and wet precipitation regimes over the southern Great Plains. The sprinkler and more aggressive flood methods lead to decreases in 2-m temperature (with respect to nonirrigated runs) that are near $5 \mathrm{~K}$ over and slightly downwind of irrigated areas, whereas the drip and less aggressive flood methods lead to 2-m temperature differences of $1-2 \mathrm{~K}$ or less. Furthermore, Harding and Snyder (2012) note a decrease in precipitation over irrigated areas and an increase in precipitation over nonirrigated areas during drought years in their modeling study that compares irrigation's impacts on precipitation and the energy budget in the U.S. Great Plains during years with below-normal, normal, and above-normal precipitation. In general, they find that impacts are most amplified with increased irrigation fraction during drought years, which is also supported by the data from the Nebraska Water and Energy Flux Measurement, Modeling, and Research Network (NEBFLUX; Irmak 2010), which showed that the largest temperature differences between two adjacent fields (one that is irrigated and one that is rainfed) from 2008-13 occurred during the 2012 central plains drought. Harding and Snyder (2012) also note an overall increase in precipitation throughout the U.S. Great Plains when incorporating irrigation in simulations, regardless of the specific precipitation regime. $\mathrm{Lu}$ et al. (2015) showed that incorporation of the observed amount of irrigated water into a crop model and the Community Land Model (CLM) in WRF can improve error in simulated mean 2-m air temperature by $\sim 0.5 \mathrm{~K}$ in irrigated areas over 2004-06 in United States, albeit with overestimates of leaf area index (LAI) values at the peak of the growing season and the length of growing season.

In summary, past research has shown that irrigation not only yields cooling at the surface but can also lead to changes in dynamics (e.g., circulations), clouds, and precipitation; these effects are more discernable at the regional scale and can vary by year and region, presumably because of the differences in large general circulations and regional climate. Building upon the previous work, this new study is unique in the following aspects.

First, the region of our study focuses on Nebraska and the nearby northern plains, which have the largest area and amount of water used for irrigation, but relatively little research has been directed at studying irrigation effects on climate for this region. Some of the only past work with a similar regional focus was conducted by Adegoke et al. (2003, 2007), who found that consideration of irrigation overall improved the Regional Atmospheric Modeling System simulation of surface temperature in the U.S. northern plains. Their model simulations are consistent with the observed temperature contrast between irrigated and nonirrigated areas for 1981-2000 (i.e., a 3.7-K cooling), but the simulations are only conducted for 0.5 month, and it is unclear how such cooling may vary in a severe drought year. The work of Lawston et al. (2015) also focused on portions of this region but only on a relatively small area of southeastern Nebraska and northeastern Kansas. Their work also focused on 2-day forecasts, whereas this work focuses on simulations over an entire summer (0000 UTC 1 June-0000 UTC 1 September 2012). The simulation domain used by Harding and Snyder (2012) also contains this region, but their work focused on impacts of irrigation throughout a domain that stretched over much of the U.S. Great Plains.

Second, by focusing on the 2012 severe droughtthe most severe drought in this region since 1895 
TABLE 1. MODIS products used in this study.

\begin{tabular}{|c|c|c|c|c|}
\hline Product & Satellite sensor & Time step & Pixel size & Citation \\
\hline MOD11C3: LST & Terra MODIS & Monthly & $0.05^{\circ}$ & Wan $(1999 ; 2009)$ \\
\hline MOD08_M3: cloud fraction & Terra MODIS & Monthly & $1^{\circ}$ & King et al. (2003) \\
\hline MOD06L2: cloud fraction & Terra MODIS & Daily & $5 \mathrm{~km}$ & King et al. (1997) \\
\hline MOD15A2: LAI & Terra MODIS & 8 days & $1 \mathrm{~km}$ & Knyazikhin et al. (1998) \\
\hline
\end{tabular}

(Hoerling et al. 2014), this study will not only examine the surface cooling due to irrigation but also can potentially improve the WRF Model simulation through 1) a more accurate spatial representation of irrigation area and 2) incorporation of crop modeling and surface observations within the LSM to account for vegetation changes during the growing season in response to both irrigation and nonirrigation scenarios. The first of those two improvements is motivated by the work of Maxwell et al. (2008); they showed that the U.S. Geological Survey 2001 National Land Cover Database underestimates cropland area by 1.4 million ha (1.8\%) as compared with the U.S. Department of Agriculture 2002 Census of Agriculture, and hence the irrigation area at the state level might be misrepresented in the default land-use database in WRF (which is shown to be the case in Nebraska). The second improvement is motivated by the fact that, in much of the past modeling work, the only difference between the default, nonirrigated scenario and irrigation scenario is the addition of water into the soil (while land surface properties are kept the same). This study also examines, by changing the vegetation canopy from cropland to native grassland, the "natural" scenario in which humans never plant crops. Overall, studying irrigation's impacts during drought provides insight into its maximum effects, as irrigation is used most during drought years. The gradient from relatively healthy crops in irrigated areas to stressed crops in nearby nonirrigated areas during severe drought also provides an opportunity to examine differences in these two areas when they are in nearly the same ambient environment. We describe in more detail our modeling approach for the two above improvements later on in section 4 .

\section{Data}

\section{a. MODIS}

Satellite datasets from Moderate Resolution Imaging Spectroradiometer (MODIS) aboard Terra for land surface temperature (LST), cloud fraction, and LAI (Myneni 2012) are used to study the characteristics of irrigated cropland during the 2012 drought in the central plains. These satellite data are used to view some of the potential meteorological effects of irrigation, such as reduction in cloud fraction over irrigated areas. Summer anomalies for
2012 are calculated using the previous 10 years as a reference, as in Wang et al. (2016). The references and pixel sizes for these datasets can be found in Table 1 .

\section{b. Ground-based observations}

Ground-based 2-m air temperature data collected by the Automated Weather Data Network (AWDN) of the High Plains Regional Climate Center are used to evaluate the uncertainty in the analysis of satellite data, as well as the accuracy of the WRF simulations. Preliminary work (Wang et al. 2016) also used 2-m air temperature measured by the NEBFLUX surface water vapor and energy flux towers (Irmak 2010). Air temperature data (from 2008 through 2013) from two NEBFLUX grassland sites were used in this preliminary work, with the two sites being geographically close to each other (within $1 \mathrm{~km}$ ) and respectively located in rainfed (dryland) and irrigated settings. The temperature contrast of approximately $1-2 \mathrm{~K}$ between these two sites in 2012 therefore provided a baseline estimate of the irrigation effect on LST.

\section{c. NARR}

Initial and boundary conditions for WRF are provided through the National Centers for Environmental Prediction (NCEP) North American Regional Reanalysis (NARR) data (ESRL 2015). The NARR dataset is "a long-term, consistent, high-resolution climate dataset for the North American domain" (Mesinger et al. 2006, p. 356). The dataset has a grid spacing of $32 \mathrm{~km}$ and a time step of $3 \mathrm{~h}$ spanning from 1979 to present.

\section{d. MODIS MIrAD}

The MODIS irrigated agriculture dataset (MIrAD) is a gridded classification of irrigated agricultural lands across the continental United States with a cell size of $250 \mathrm{~m}$ that makes use of the National Land Cover Dataset, USDA Census of Agriculture irrigated area statistics, and annual maximum vegetation index calculated from MODIS imagery (https://earlywarning.usgs.gov/USirrigation; accessed 30 July 2015) (Brown et al. 2009; Pervez and Brown 2010; Brown and Pervez 2014). This dataset, merged with the default WRF land-use dataset, is used as the land-use dataset in this study. The MIrAD dataset represents areas of irrigation in Nebraska more 


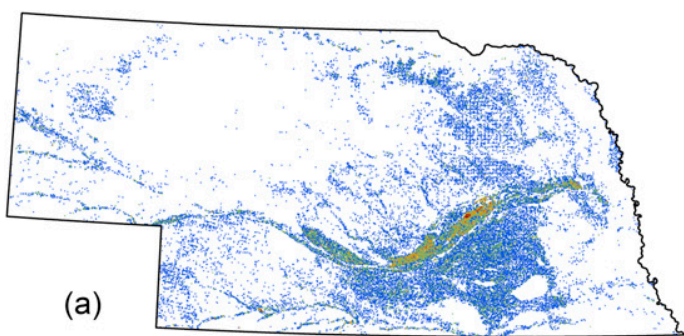

Irrigation Wells per sq. km $0-1 \square 2-3 \square 4-7$ $\square-15 \square 16+$
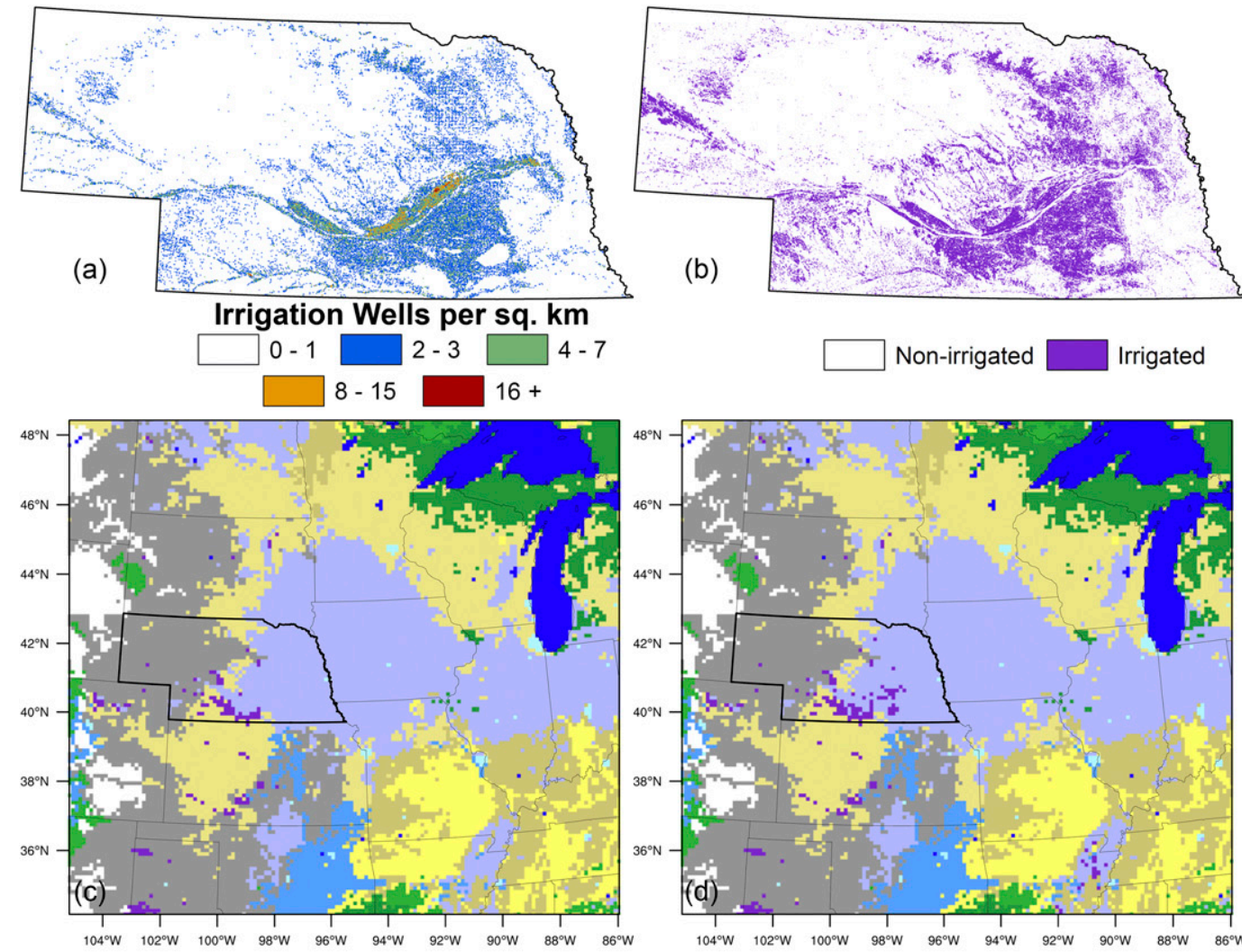

(b)
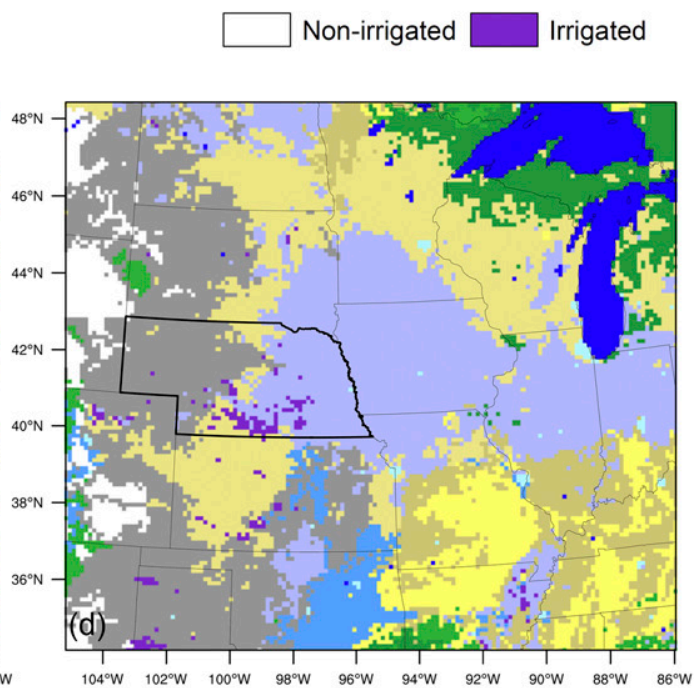
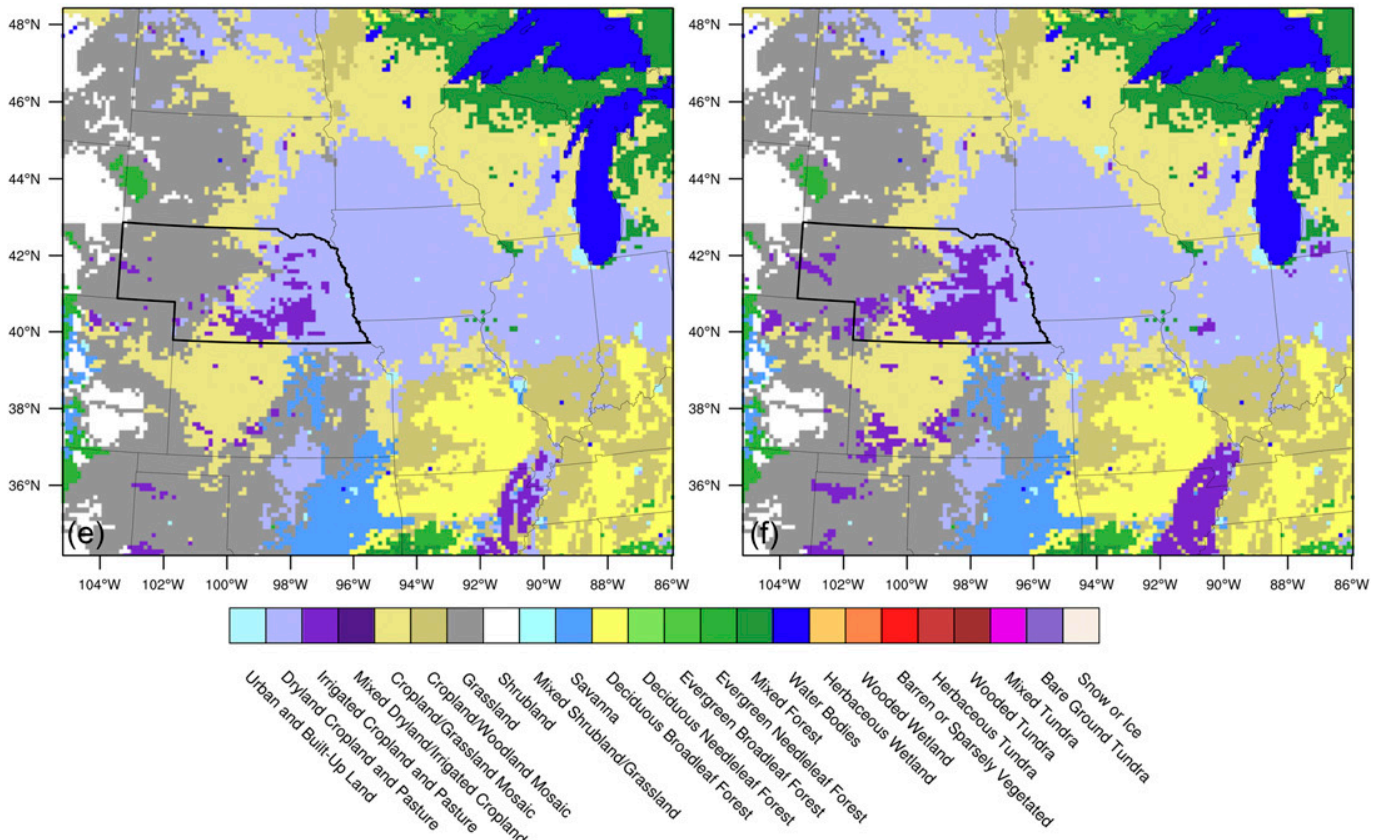

FIG. 1. (a) Density of registered irrigation wells in Nebraska per square kilometer, (b) MIrAD for Nebraska, and (c) WRF default land-use dataset for the simulation domain. Also shown are land-use datasets using (d) $75 \%$, (e) $50 \%$, and (f) $25 \%$ thresholds for classification of WRF land use as "irrigated cropland and pasture" (e.g., for the $75 \%$ threshold, $75 \%$ of the MIrAD pixels within a single WRF pixel must be classified as "irrigated" for the WRF pixel to be classified as irrigated cropland and pasture). 
TABLE 2. Configuration of WRF and physics schemes used.

\begin{tabular}{ll}
\hline \hline WRF version & 3.6 .1 \\
Grid increment & $12 \mathrm{~km}$ \\
Simulation dates & 0000 UTC 1 Jun-0000 UTC \\
& 1 Sep 2012 \\
Boundary conditions & NARR \\
LSM & CLM 4.0 \\
Microphysics & WRF single-moment 3-class scheme \\
Longwave radiation & Rapid Radiative Transfer Model \\
Shortwave radiation & Dudhia scheme \\
PBL & Yonsei University scheme \\
Cumulus parameterization & Kain-Fritsch scheme \\
\hline
\end{tabular}

accurately than does the default land-use dataset in WRF (Fig. 1) and has been shown to have relatively good (82\%) pixel agreement with a Landsat-derived land-use dataset in Nebraska (Wardlow and Callahan 2014). Correctly representing areas of irrigation is vital when attempting to verify model output with observations.

\section{Model and methods}

\section{a. WRF Model}

The WRF Model, version 3.6.1, run using a 12-km grid increment, is used to simulate the potential effects of irrigation during the summer of 2012 (0000 UTC 1 June0000 UTC 1 September 2012). A single domain containing a $134 \times 149$ grid with $12-\mathrm{km}$ grid spacing $(1620 \mathrm{~km} \times$ $1800 \mathrm{~km}$ ) over the central plains of the United States is used in this study, although much of the analysis is confined to Nebraska (Figs. 1c-f). The WRF Model is a regional model used for both research and operational forecasting (Skamarock et al. 2008). Although originally designed as a mesoscale forecast model, WRF has been adapted for use in climate studies. This work seeks to more accurately represent the irrigation surface through the use of the CLM, version 4.0 (Oleson et al. 2010; Lawrence et al. 2011). CLM also has a sophisticated surface albedo scheme, enhanced terrestrial water cycle, canopy interception and integration, runoff from the surface and subsurface, groundwater and water-table depth, soil water availability and soil evaporation, inclusion of carbon and nitrogen cycle dynamics that improves plant production and LAI, and frozen soil modifications. Aside from the LSM, the physics and parameterization schemes used are the WRF defaults (Table 2).

\section{b. Irrigation area and parameterization}

By default, WRF uses land-use categories from U.S. Geological Survey (USGS) 24-category data. These data have a grid spacing of $1 \mathrm{~km}$ and are based on data collected by the Advanced Very High Resolution Radiometer between April of 1992 and March of 1993
(USGS 2016). Therefore, this database is out of date, and, as shown in Fig. 1, it does not represent the irrigated areas that were present in 2012, which is necessary to be able to compare simulation results with observational data. To better represent irrigation in WRF, the USGS dataset is merged with MIrAD (Fig. 1). The merger process was carried out through requiring a certain number of MIrAD pixels within a WRF grid box to be classified as "irrigated" so as to classify the land use in that grid box in WRF as "irrigated cropland and pasture." For example, a threshold of $25 \%$ required $25 \%$ of the $250-\mathrm{m}$ MIrAD pixels contained within a WRF grid box $(12-\mathrm{km}$ grid spacing) to be classified as irrigated to allow classification of that entire WRF grid box as irrigated cropland and pasture. In total, three different thresholds- $25 \%, 50 \%$, and $75 \%$-were used in this merger process. Results of these three mergers were subjectively compared with the spatial distribution of irrigation-well density and raw MIrAD data to determine which threshold to use in noncontrol WRF simulations. The $25 \%$ threshold seemed to match the best, even containing the "hole" of nonirrigated land (classified as "dryland cropland and pasture") present at the southeastern edge of the large irrigated area in southeastern Nebraska, and therefore it is used as the land-use dataset in irrigated WRF runs.

Recent advancements in the complexity of LSMs have led to several attempts to accurately parameterize irrigation. One of the most popular ways to parameterize irrigation is simply to add soil moisture at a specified time interval, or possibly to keep soil moisture constant, in irrigated areas (Adegoke et al. 2003; Jiang et al. 2014; Kueppers et al. 2007; Kueppers and Snyder 2012; Zaitchik et al. 2005). Other methods include adding water as precipitation in irrigated areas (Ozdogan et al. 2010 ) and increasing evapotranspiration (ET) or vapor flux over irrigated areas (Douglas et al. 2006; Segal et al. 1988; Evans and Zaitchik 2008).

Lawston et al. (2015) studied three of the main parameterizations of irrigation (drip, flood, and sprinkler) by using 5-yr spinups of NASA's Land Information System to initialize 2-day WRF forecasts at 1-km grid spacing over the Great Plains of the United States. The "drip" method was implemented through adding the exact amount of water required to avoid soil moisture stress (calculated by finding the difference between canopy resistance using current soil moisture and canopy resistance assuming no soil moisture stress and then finding these resulting ET values). Two "flood" methods were implemented through adding enough water to saturate the root zone if the soil moisture in this area fell below $25 \%$ above the wilting point (Flood 25 ) or $75 \%$ of the wilting point (Flood75). The "sprinkler" method added water as precipitation at a user-specified rate 

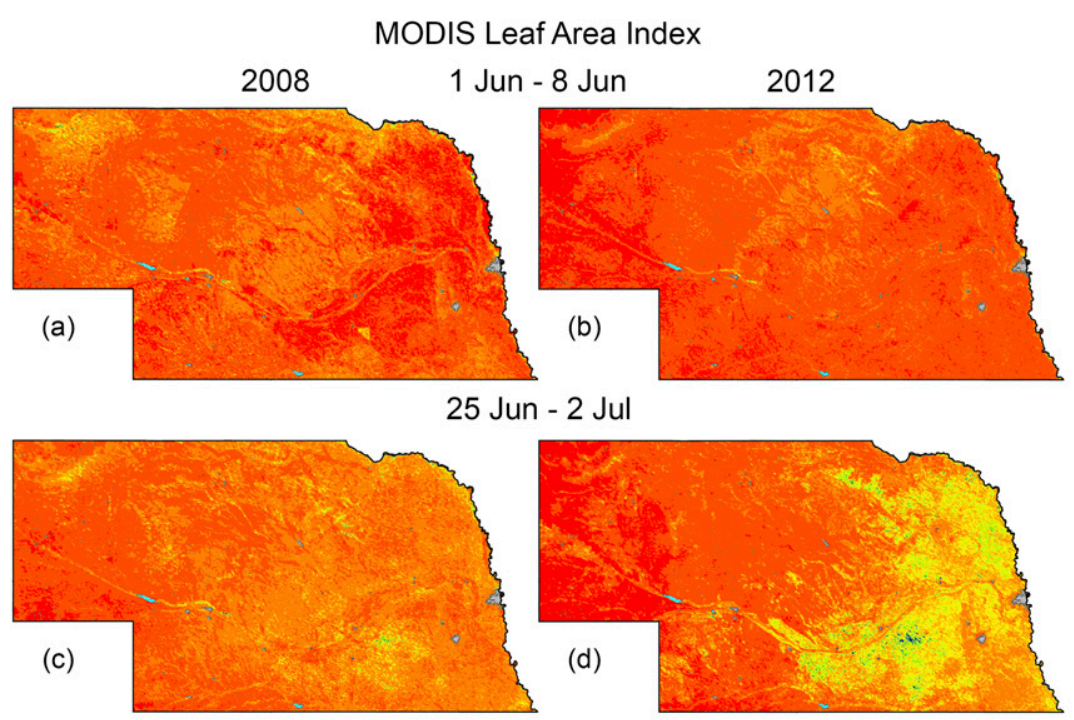

27 Jul - 3 Aug

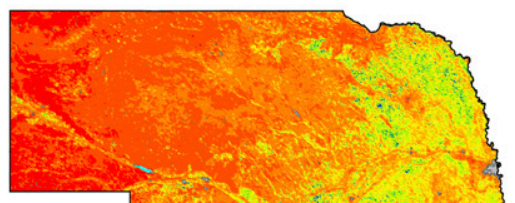

(e)
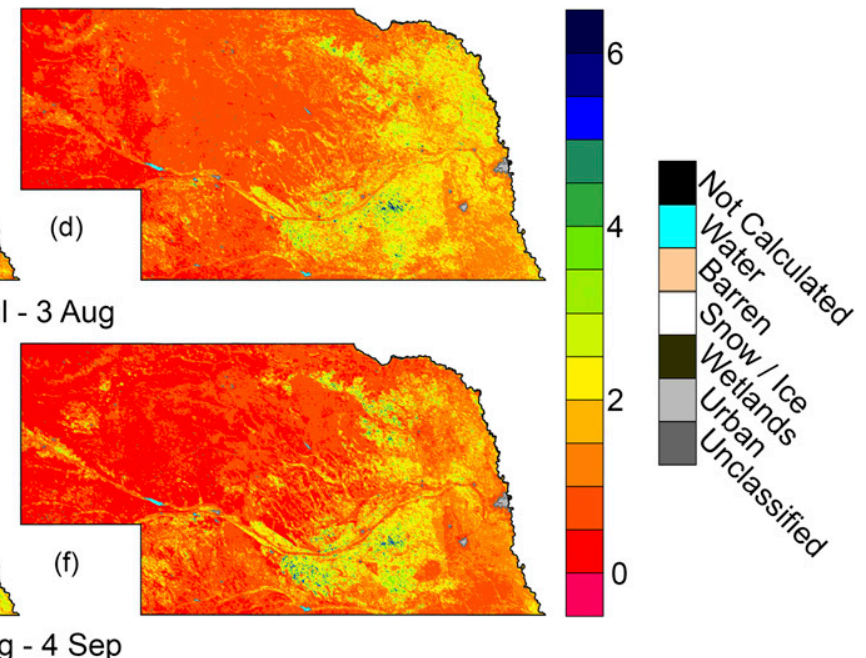

28 Aug - 4 Sep
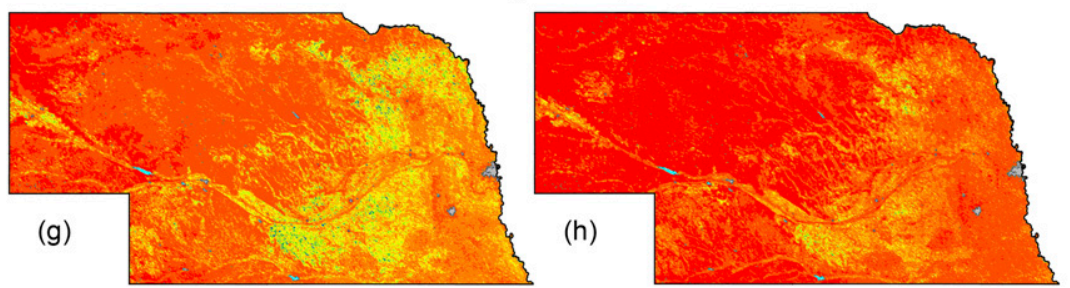

FIG. 2. The 8-day average LAI from MODIS aboard Terra for (a),(c),(e),(g) summer of 2008 and (b),(d),(f),(h) summer of 2012. The year 2008 is a normal precipitation year in Nebraska, as described in the text.

$\left(5 \mathrm{~mm} \mathrm{~h}^{-1}\right.$ in the study) when root zone moisture availability (RZMA) fell below 10\% above the stress point until RZMA reached $80 \%$ of the soil moisture capacity.

For this study, additional moisture from irrigation is parameterized through increasing soil moisture in irrigated areas in all layers (ranging from 0 to $3.433 \mathrm{~m}$ ) to $50 \%$ of soil moisture capacity if this area falls below $50 \%$ of soil moisture capacity (where soil moisture capacity is determined by porosity of the soil in a given area). Therefore, soil moisture in irrigated areas can be greater than $50 \%$ of soil moisture capacity during precipitation events. Although many previous studies force soil moisture to saturation (i.e., $100 \%$ of soil moisture capacity), $50 \%$ is used in this study because entire fields (much less entire $12-\mathrm{km}$ grid squares) are not saturated instantaneously through irrigation given that center-pivot irrigation, which is the most common irrigation method $(87.7 \%)$ in Nebraska, can take nearly 2 days to water an entire field (USDA 2014). Although not as complex as other irrigation parameterizations, this simple-toimplement method (combined with modified LAI values discussed in section $4 \mathrm{c}$ ) is the first step toward future studies to implement more-realistic irrigation schemes. Indeed, no consensus can be found in literature on how irrigation should be added in the LSM.

\section{c. Temporal variation of LAI}

One of the main phenological impacts of irrigation is usually the increase of leaf size and thus LAI relative to nonirrigated plants, especially during drought. MODIS data provide an excellent way to monitor these changes in LAI throughout a given growing season (Fig. 2). In a 
normal precipitation year, such as 2008, croplands show a distinct seasonal cycle of greenness (in terms of green LAI): no discernable greenness from space in early June (Fig. 2a), some greenness (with LAI value of 2) in late June and early July (Fig. 2c), maximal greenness (with LAI value of up to 4-5) in late July and early August (Fig. 2e), and then decrease of greenness (with LAI value less than 4) in late August and early September (Fig. 2g). The "normal" year of 2008 was selected by finding the smallest precipitation departure from normal in Nebraska from 2002 through 2011 (NCEI 2016). Consequently, the dryland cropland in northeastern Nebraska is much more difficult to distinguish from the irrigated area in southeastern Nebraska when simply looking at LAI values in 2008 (Figs. 2e,g).

In the drought year of 2012 in contrast, although the greenness of crops indeed started earlier (Fig. 2d) when compared with 2008 (Fig. 2c), the dryland cropland (much of northeastern Nebraska) dies off during the peak of growing season and the irrigated area in southeastern Nebraska remains relatively healthy (as revealed from comparison between Fig. 2f for 2012 and Fig. 2e for 2008).

Since changes in LAI occur on the basis of the soil and precipitation conditions, this response is considered by changing the prescribed LAI time series in the simulation. Two approaches are used, with one being based on satellite-based observation (CLM default) and the other on a simulation by the Hybrid-Maize crop model (Yang et al. 2004) for various meteorological conditions in 2012. Using a crop model is an improvement over the satellite-derived LAI climatological description because the model is able to more accurately capture variation from year to year, especially during an "extreme" year that experiences drought or flooding. The Hybrid-Maize model simulates corn growth under irrigated as well as nonirrigated conditions on the basis of the following daily weather variables: maximum air temperature, minimum air temperature, total solar radiation, rainfall, potential evapotranspiration, and relative humidity. The Hybrid-Maize model is well validated through comparison of its LAI output, along with the output of two other crop models [Interplant Competition (INTERCOM; Kropff and van Laar 1993) and Crop Estimation through Resource and Environment Synthesis (CERES)-Maize (Jones and Kiniry 1986)], with observations from three fields with varying plant density in Lincoln, Nebraska, for 1999-2001. Overall, Hybrid-Maize showed an average modeling efficiency (similar to correlation coefficient squared $r^{2}$ ) of 0.903 over the three years, whereas INTERCOM and CERES-Maize showed average modeling efficiencies of 0.703 and 0.74 , respectively, although all models tended to underpredict maximum LAI values (Yang et al. 2004). Much of the irrigated area in Nebraska contains both corn and soybeans, and the LAI values for corn from the Hybrid-Maize model can be representative of both corn and soybeans, given the assumption that the crops are planted at a similar time (soybeans are commonly planted immediately after corn in Nebraska).

Figure 3 illustrates the differences in LAI values used by default in CLM, those simulated by the Hybrid-Maize model, and those detected via MODIS. The MODIS LAI values shown in Fig. 3 are 8-day averages within three areas of cropland-one irrigated and two nonirrigated-that are shown in Fig. 3b. The areas were selected on the basis of land-use categories in the $25 \%$ merged land-use dataset that was used in several of the WRF simulations in this study. The irrigated area is within the main area of irrigation in southeastern Nebraska. The nonirrigated area in $\mathrm{Ne}$ braska is a small, nonirrigated area of cropland on the southeastern edge of the main irrigated area in $\mathrm{Ne}$ braska. Because this area is essentially surrounded by the main area of irrigation in Nebraska, it provides an almost ideal area for comparison with the irrigated area, because both areas experience nearly the same ambient meteorological conditions. Because of its small areal extent, however, the nonirrigated area contains very few MODIS pixels, and therefore the LAI averages for another nonirrigated area of cropland (located in northern central Iowa) are also calculated. Because the default CLM irrigated (dryland) LAI is weighted as $85 \%$ irrigated (dryland) cropland and $15 \%$ urban area (LAI of 0 ), the Hybrid-Maize data are weighted the same way for a more direct comparison.

Although the default CLM values seem to compare somewhat closely to those observed by MODIS, note that these MODIS observations are from a drought year (2012), and so the actual values are likely greater than those used by CLM. Also, by default, CLM uses the same LAI values for both irrigated and dryland areas, which is clearly not the case in a drought year such as 2012. Nevertheless, both MODIS observations and crop models consistently show that irrigated crops (purple shaded and blue line in Fig. 3a) have larger LAI values and a longer growing season (before LAI decreases to 1) than their counterparts of nonirrigated dryland crops (pink shaded and red line in Fig. 3a). In addition, while the Hybrid-Maize model overall provides larger LAI values in the peak of growing season than do corresponding satellite observations (whether irrigated land or dry land), both satellite and Hybrid-Maize model 


\section{Leaf Area Index Comparison}

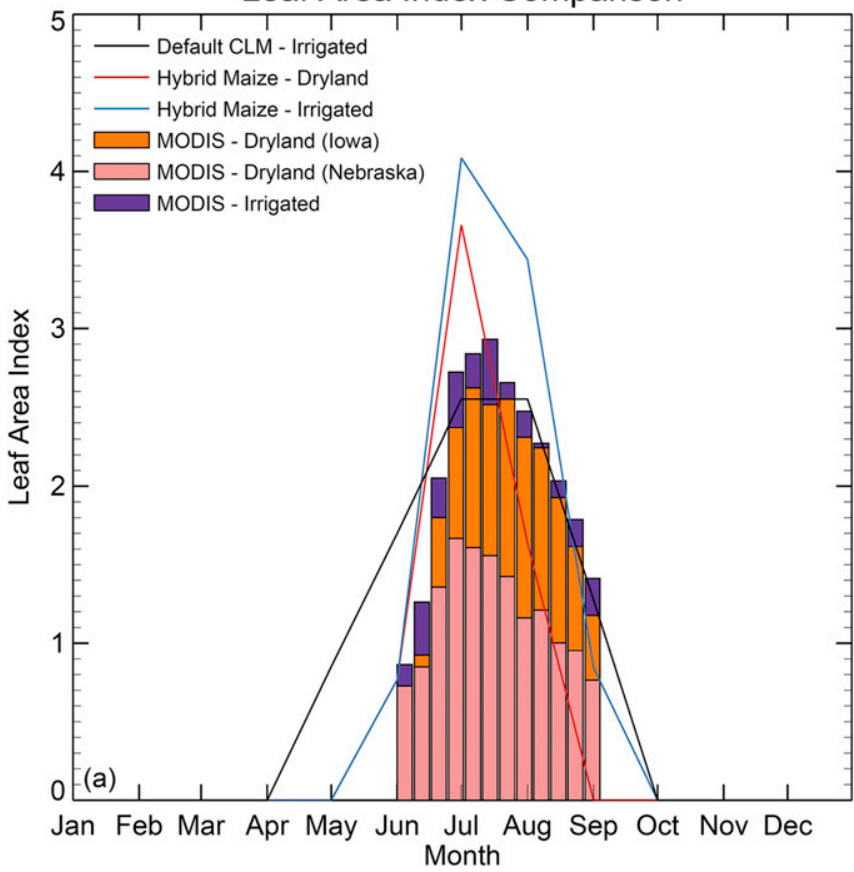

(b)

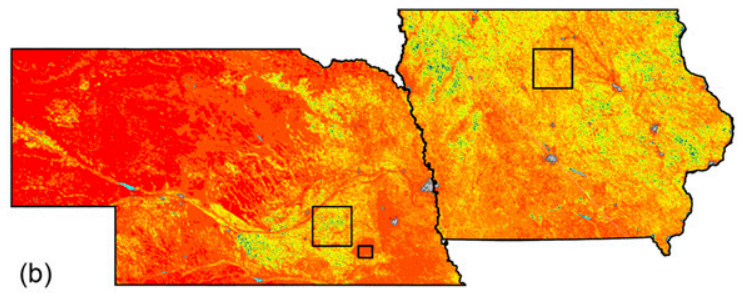

FIG. 3. (a) Comparison of several modeled/MODIS-derived LAI values. Shown are the default input irrigated and dryland cropland LAI used in CLM (black line), the irrigated LAI for summer 2012 from Hybrid-Maize crop model simulations as used in CLM (solid blue line), dryland LAI for summer 2012 from Hybrid-Maize crop model simulations as used in CLM (solid red line), MODIS irrigated 8-day average LAI for summer 2012 (purple bars), MODIS dryland (Iowa) 8-day average LAI for summer 2012 (orange bars), and MODIS dryland (Nebraska) 8-day average LAI for summer 2012 (pink bars). (b) Areas representing irrigated (large box) and dry land (small box) in Nebraska, as well as a dryland area in Iowa.

simulations show that LAI values over irrigated areas are larger than those over dryland cropland. The CLMdefault time series of LAI (black line in Fig. 3a) is not consistent with either satellite-based or crop-modeling analysis because it shows a growing season with a starting date in early April and an ending date in late October. We therefore replace the CLM-default LAI time series for both irrigated and dryland cropland with their respective time series as simulated by the HybridMaize model and assess the impact of these replacements in the simulation. While incorporating the dynamic crop responses in the model as was done by $\mathrm{Lu}$ et al. (2015) can be a future research topic, the method we use here certainly offers more accuracy, especially in a drought year, than using the default satellite-derived climatological LAI values.

\section{d. Numerical experiment design}

This study analyzes output from seven WRF simulations, as summarized in Table 3.1) WRF-DF (default) is simply WRF, version 3.6.1, as downloaded (with default land use and the default satellite-derived leaf area values in CLM). 2) WRF-DF-50S is the same as WRFDF but also makes use of an irrigation parameterization scheme that increases soil moisture to $50 \%$ of soil moisture capacity if soil moisture falls below $50 \%$ of soil moisture capacity. 3) WRF-Ctrl serves as the control simulation and is the same as WRF-DF but makes use of

TABLE 3. WRF runs in the sensitivity experiment.

\begin{tabular}{llll}
\hline \hline \multicolumn{1}{c}{ Run name } & & \multicolumn{1}{c}{ Loil moisture } & \multicolumn{1}{c}{ LAI } \\
\hline WRF-DF & Default & Default & Default \\
WRF-DF-50S & Default & Increase to 50\% if $<50 \%$ & Default \\
WRF-Ctrl & MIrAD & Default & Default \\
WRF-DS-HLAI & MIrAD & Default & Hybrid-Maize \\
WRF-50S-DLAI & MIrAD & Increase to 50\% if $<50 \%$ & Default \\
WRF-50S-HLAI & MIrAD & Increase to 50\% if $<50 \%$ & Hybrid-Maize \\
WRF-Natural & Nebraska irrigated cropland becomes grassland & Default & Default \\
\hline
\end{tabular}




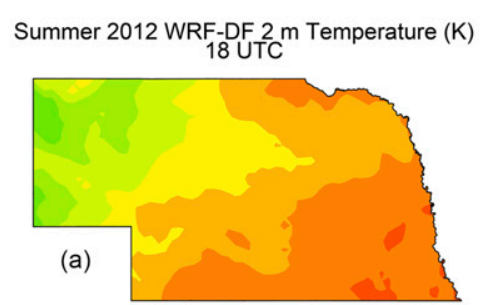

Summer 2012 WRF-Ctrl $2 \mathrm{~m}$ Temperature (K)

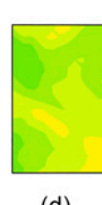

(d)

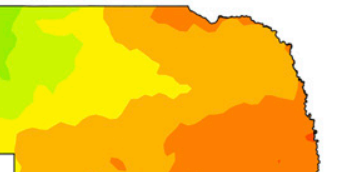

(1)
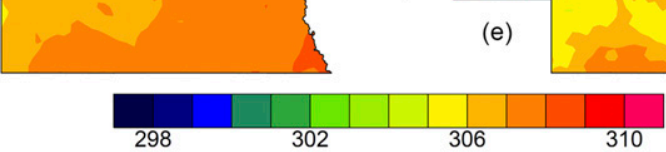

Summer 2002-2011 MODIS LST (K)

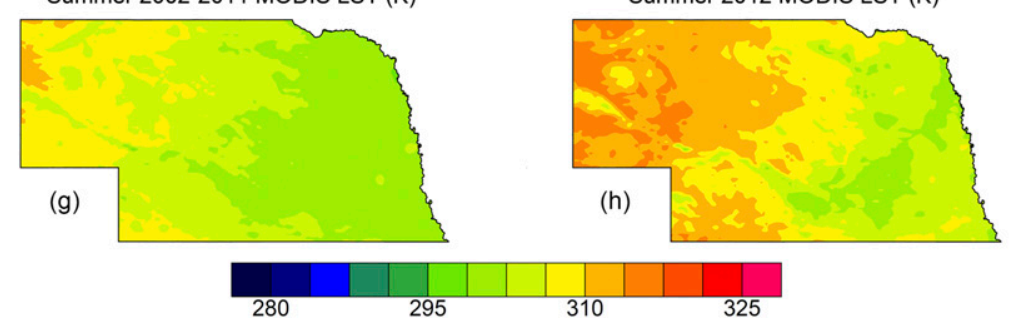
Summer 2012 WRF-DF-50S 2 m Temperature (K)

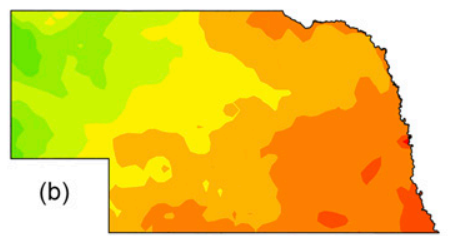

Summer 2012 WRF-50S-DLAI 2 m Temperature (K)

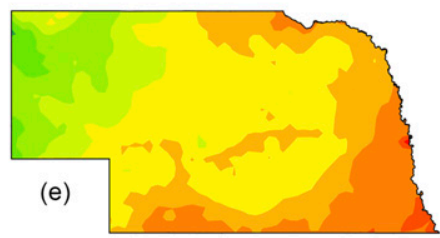

310

Summer 2012 WRF $2 \mathrm{~m}$ Temperature Difference (K)

FIG. 4. Simulated summer 2012 2-m temperature averaged at 1800 UTC in Nebraska for (a) WRF-DF and (b) WRF-DF-50S. (c) WRFDF-50S and WRF-DF 2-m temperature difference for summer 2012 at 1800 UTC [(b) minus (a)]. (d)-(f) As in (a), (b), and (c), but for WRF-Ctrl and WRF-50S-DLAI. (g) Summer 2002-11 average LST, (h) summer 2012 average LST, and (i) summer 2012 LST anomaly [(h) minus (g)] from Terra MODIS. Note that different scales are applied to the color bar for $T_{2 \mathrm{~m}}$ and LST.

the $25 \%$ threshold USGS-MIrAD merged land-use dataset as discussed in section $4 \mathrm{~b}$. This merged land-use dataset is also used in the three following simulations. 4) WRF-DS-HLAI (default soil moisture and Hybrid-Maize LAI) once again uses default soil moisture but makes use of Hybrid-Maize model-simulated LAI values for irrigated and nonirrigated cropland. 5) WRF-50S-DLAI (50\% soil moisture and default LAI) and 6) WRF-50SHLAI (50\% soil moisture and Hybrid-Maize LAI) use the default LAI and Hybrid-Maize model-simulated LAI values, respectively, but also make use of the irrigation parameterization scheme used in WRF-DF-50S. 7) WRFNatural makes use of a land-use dataset in which all irrigated cropland in Nebraska and immediately surrounding areas is converted to grassland. Soil moisture and LAI values are not modified in this simulation. This is meant to simulate a hypothetical situation in which humans are not able to grow crops in irrigated areas (i.e., humans only planted crops in those areas because groundwater for irrigation was available). Unless otherwise noted, the WRF simulation results are averaged at 1800 UTC for a more direct comparison with data collected from Terra MODIS because 1800 UTC is the approximate overpass time of Terra for Nebraska. Note also that soil moisture values are initiated by using the counterparts from NARR, and model-simulated soil moisture in the WRF-50S-HLAI run is comparable to the AWDN observations, with a slight overestimation of $0.009 \mathrm{~m}^{3} \mathrm{~m}^{-3}$ (or $7 \%$ ) when comparing the 0.091-0.166-m layer in CLM with the 0.10-m soil moisture observation from AWDN. In the irrigation areas, the difference between simulated and observed soil moisture is found to be less than $5 \%$ for most stations (Fig. S1 in the online supplemental material).

\section{Impacts on temperature}

\section{a. Impact from additional soil moisture}

WRF simulations of summer-averaged 2-m temperature $T_{2 \mathrm{~m}}$ at 1800 UTC in Nebraska show temperature decreases throughout the state (relative to WRF-DF and WRF-Ctrl) when incorporating the " $50 \mathrm{~S}$ " irrigation parameterization 
Summer 2012 WRF-DS-HLAI 2 m Temperature (K) 18 UTC

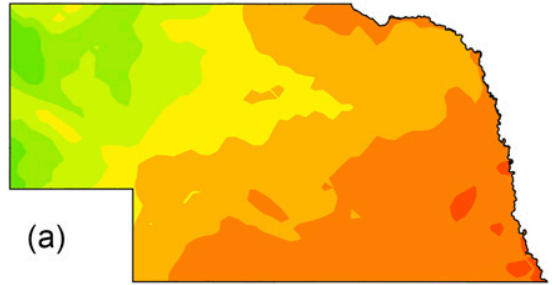

Summer 2012 WRF-50S-HLAl 2 m Temperature (K) 18 UTC

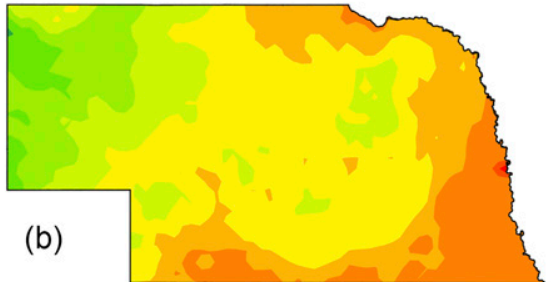

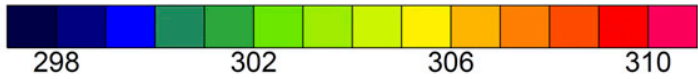

Summer 2012 WRF $2 \mathrm{~m}$ Temperature Difference (K) Summer 2012 WRF $2 \mathrm{~m}$ Temperature Difference (K) (WRF-50S-HLAl-WRF-Ctrl)

(WRF-50S-HLAl - WRF-DS-HLAI)
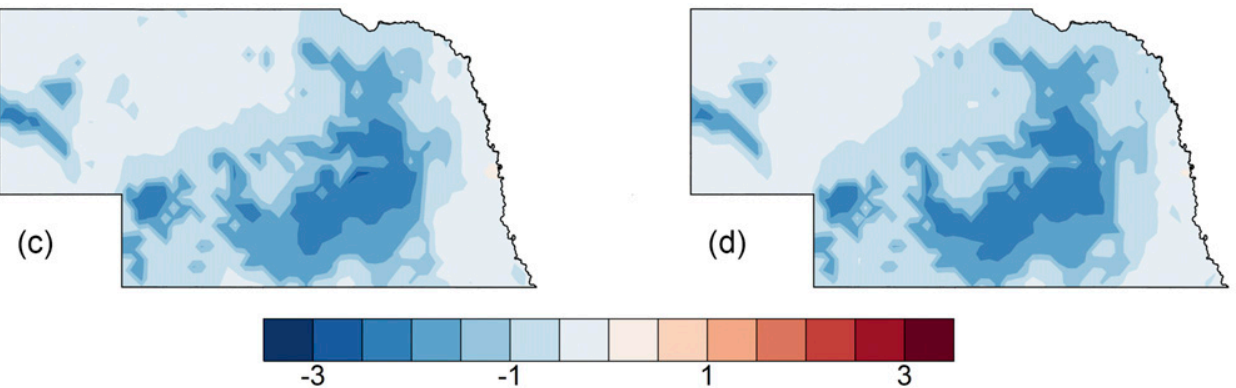

Summer 2012 WRF $2 \mathrm{~m}$ Temperature Difference (K) Summer 2012 WRF $2 \mathrm{~m}$ Temperature Difference (K) (WRF-50S-HLAl-WRF-50S-DLAI)

(WRF-DS-HLAl-WRF-Ctrl)
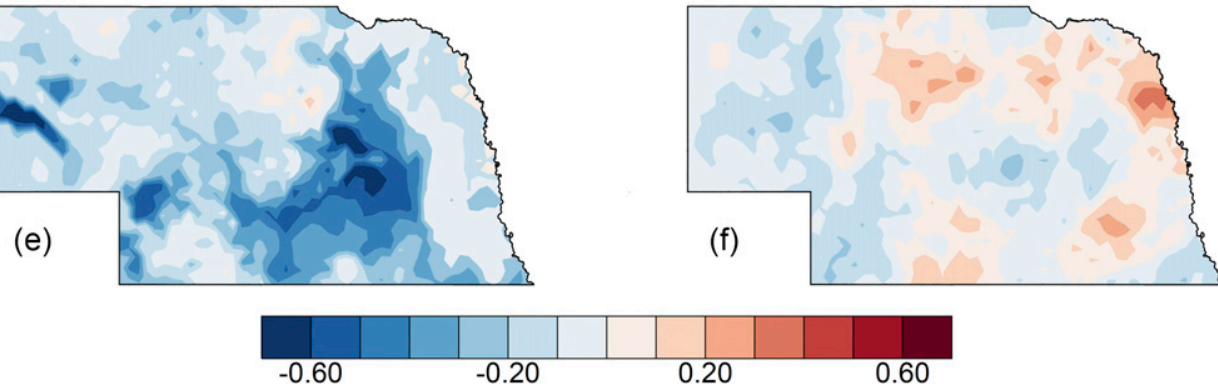

FIG. 5. Simulated summer 2012 2-m temperature averaged at 1800 UTC in Nebraska for (a) WRF-DS-HLAI and (b) WRF-50S-HLAI, and simulated summer 2012 2-m temperature difference averaged at 1800 UTC for (c) WRF50S-HLAI and WRF-Ctrl, (d) WRF-50S-HLAI and WRF-DS-HLAI, (e) WRF-50S-HLAI and WRF-50S-DLAI, and (f) WRF-DS-HLAI and WRF-50S-Ctrl. Note that the scales that are applied to the color bars for (c) and (d) are different than those for (e) and (f).

(Fig. 4). Comparison between WRF-DF-50S (Fig. 4b) and WRF-DF (Fig. 4a) shows a 1-K decrease of $T_{2 \mathrm{~m}}$ due to irrigation immediately over the default land-use irrigated area located in southwestern Nebraska (Fig. 4c). Although the default irrigation area is not in the correct location, the decrease of $T_{2 \mathrm{~m}}$ does illustrate that CLM physics is operating as expected (i.e., more soil moisture leads to more latent heating/less sensible heating and, therefore, cooler temperatures). Simply introducing an irrigated area that is more spatially accurate (WRF-Ctrl), as shown in Fig. 4d, does not lead to any noteworthy temperature difference in
Nebraska as a whole, but combining the modified land use with the 50S irrigation parameterization (WRF-50SDLAI, Fig. 4e) leads to a nearly 2-K temperature decrease over the most densely irrigated area in southeastern Nebraska (Fig. 4f); the geographical distribution of this $T_{2 \mathrm{~m}}$ decrease is in good agreement with the Terra MODIS LST anomalies (Fig. 4i), which are between 0 and $2 \mathrm{~K}$ for a10-yr (2002-11) average of LST (Fig. 4g). Furthermore, comparison of these simulations with MODIS LST unsurprisingly shows that, among all four numerical experiment results in Fig. 4, WRF-50S-DLAI (Fig. 4e) is 

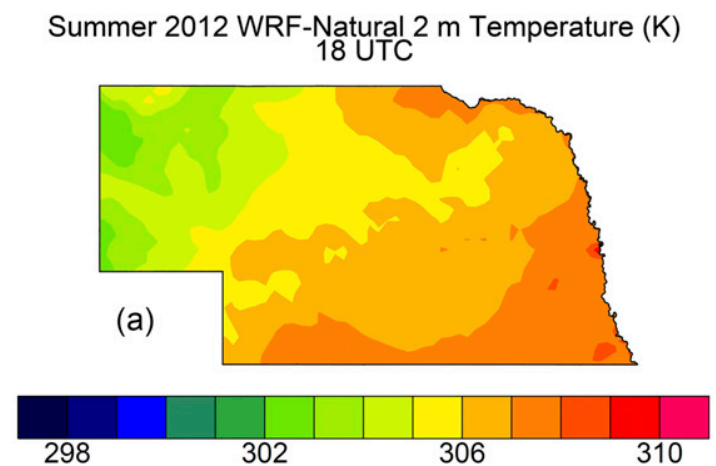

Summer 2012 WRF $2 \mathrm{~m}$ Temperature Difference (K) Summer 2012 WRF $2 \mathrm{~m}$ Temperature Difference (K) (WRF-Natural-WRF-Ctrl)

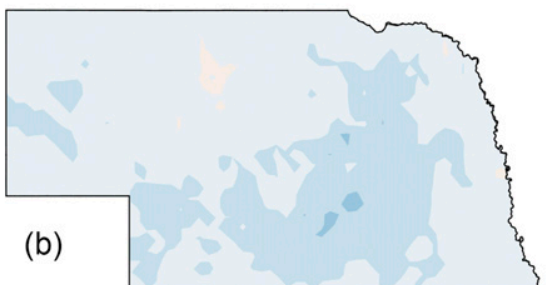
(WRF-Natural - WRF-50S-HLAI)
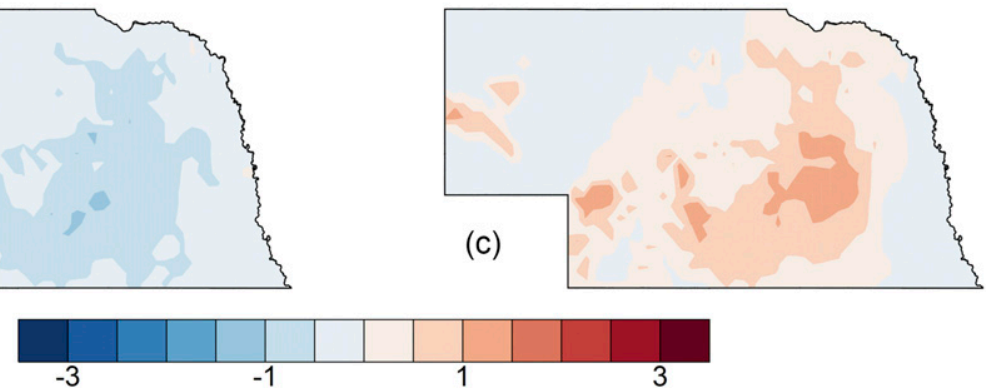

3

FIG. 6. (a) Simulated summer 2012 2-m temperature averaged at 1800 UTC in Nebraska for WRF-Natural, and simulated summer 2012 2-m temperature difference averaged at 1800 UTC for (b) WRF-Natural and WRF-Ctrl and (c) WRF-Natural and WRF-50S-HLAI.

the closest to MODIS LST in the irrigated areas (Fig. 4h) in terms of spatial distribution of temperature. Note that, because MODIS's LST is a retrieval parameter and reflects the radiation emitted from both canopy and land surface itself, there is no WRF parameter that can be directly quantitatively compared with MODIS LST for all areas. We use $T_{2 \mathrm{~m}}$ here because that is the parameter often measured by weather stations and thus can be evaluated with these observations.

\section{b. Impact from LAI modification}

Modification of LAI in CLM to use values simulated by the Hybrid-Maize model leads to a distribution of $T_{2 \mathrm{~m}}$ in Nebraska that is similar to that of the WRF-Ctrl simulation (Fig. 5a and Fig. 4d). Overall, modified LAI has a much smaller impact on temperature (Fig. 5f) than adding soil moisture to simulate irrigation (Fig. 4f). Despite the relatively small impact on temperature, one unique aspect of the modified LAI is that, whereas all other simulations led to cooler temperatures throughout Nebraska, WRFDS-HLAI actually led to warming in some areas. Small $T_{2 \mathrm{~m}}$ increases of up to $0.5 \mathrm{~K}$ in a few spots can be seen in dryland areas in eastern Nebraska-likely due to crops in the dryland areas beginning to grow later and dying earlier than in the WRF-Ctrl run (as seen in
Fig. 3a)-although the magnitude of these temperature increases is not that significant (Fig. 5f). When combining the addition of soil moisture to the modification of LAI (Fig. 5b), the changes in 2-m temperature are much more significant, with small areas of temperature decrease in southeastern Nebraska of $>2.5 \mathrm{~K}$ when compared with WRF-Ctrl (Fig. 5c). Comparison of WRF-50S-HLAI with WRF-DS-HLAI is another way to quantify the impact of adding soil moisture; this comparison shows a temperature decrease that is greater than $2 \mathrm{~K}$ (Fig. 5d). The comparison of WRF-50S-HLAI with WRF-50S-DLAI shows a temperature decrease near $0.5 \mathrm{~K}$ through much of the irrigated areas (Fig. 5e). This particular decrease is interesting, because simply changing the LAI in 50S runs leads to a larger temperature decrease than doing the same in non-50S runs. One hypothesis to explain this result is that with larger leaves plants will transpire more, leading to increased evapotranspiration. Because the soil moisture is increased in the $50 \mathrm{~S}$ runs, there is more soil moisture available for evapotranspiration, and thus a greater cooling effect is observed.

\section{c. Contrast with nonirrigated cropland}

As previously mentioned, the WRF-Natural run is meant to simulate what would happen if farmers never 


\section{Summer 2012 WRF-Ctrl $850 \mathrm{hPa}$ Temperature (K) 18 UTC}
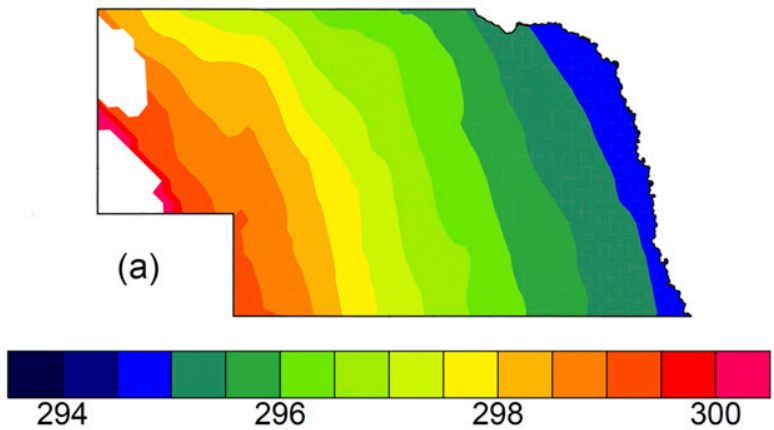

\section{Summer $2012 \mathrm{WRF} 850 \mathrm{hPa} \mathrm{T}(\mathrm{K})$ (WRF-DS-HLAl - WRF-Ctrl)}

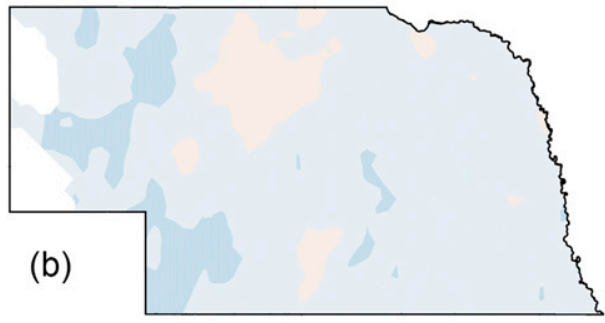
Summer $2012 \mathrm{WRF} 850 \mathrm{hPa} \mathrm{T}(\mathrm{K})$ (WRF-50S-HLAl - WRF-Ctrl) 18 UTC

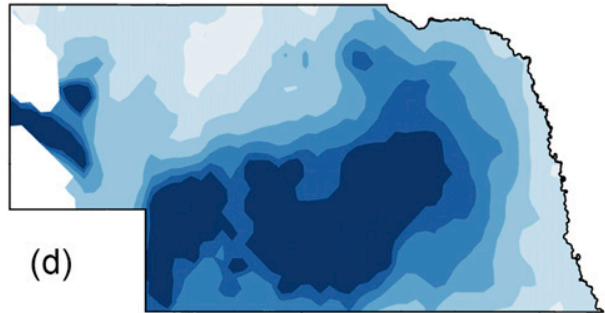
Summer 2012 WRF $850 \mathrm{hPa} T(\mathrm{~K})$
(WRF-50S-DLAI-WRF-Ctrl)
18 UTC

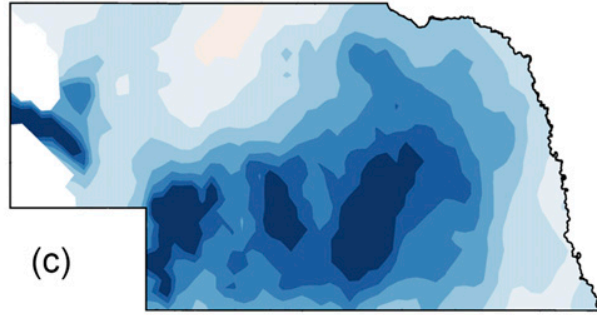

Summer $2012 \mathrm{WRF} 850 \mathrm{hPa} T(\mathrm{~K})$ (WRF-Natural-WRF-Ctrl) 18 UTC

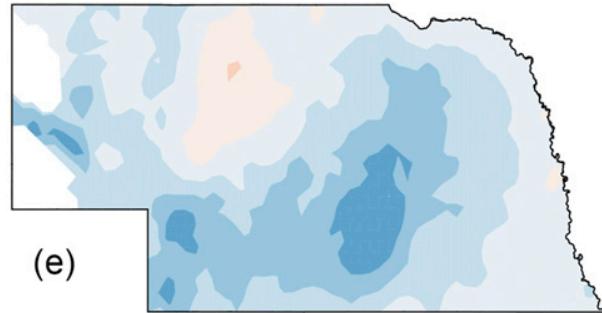

(e)

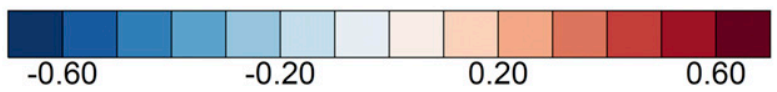

FIG. 7. (a) Simulated summer 2012 850-hPa temperature averaged at 1800 UTC for WRF-Ctrl, and simulated summer 2012850 -hPa temperature difference vs WRF-Ctrl averaged at 1800 UTC for (b) WRF-DS-HLAI, (c) WRF-50S-DLAI, (d) WRF-50S-HLAI, and (e) WRF-Natural. Note that areas in which surface pressure is less than $850 \mathrm{hPa}$ are not plotted.

planted crops in the present-day irrigated areas and instead these areas were grasslands, the likely "native" land use in these areas. This could also be a hypothetical scenario in which the groundwater resources in Nebraska become too depleted to sustain irrigation practices. No major changes with respect to WRF-Ctrl in $T_{2 \mathrm{~m}}$ distribution are observed in the WRF-Natural simulation (Fig. 6a). When compared with WRF-Ctrl, the grassland substitution leads to a $1-\mathrm{K}$ cooling effect over the area (Fig. 6b). This further illustrates the model's inability to handle irrigated cropland using the default WRF-CLM setup, even with land use changed to give a more accurate spatial representation of irrigation, as it would be expected that grassland would be warmer than irrigated cropland. In contrast, and as expected, when comparing the WRF-Natural simulation with WRF-50S-HLAI, higher $T_{2 \mathrm{~m}}$ values are present where irrigated cropland was replaced with grassland (Fig. 6c). Most of this temperature difference can likely be attributed to much lower soil moisture values in the WRF-Natural run, although the grassland land use in CLM also has lower LAI values when compared with the Hybrid-Maize values 
AWDN Station Land-Use in WRF

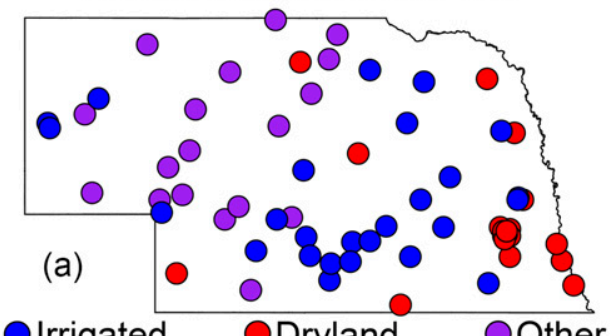

Irrigated

Summer $20122 \mathrm{~m}$ Temperature Difference (K)

(WRF-DS-HLAl - AWDN)

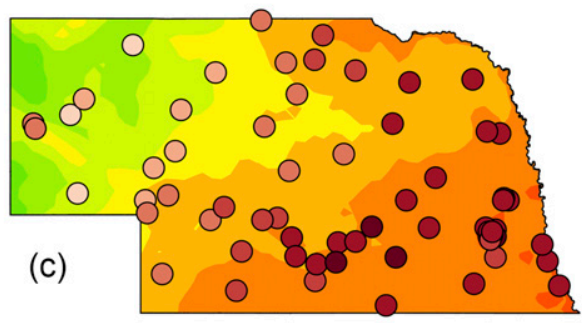

Summer $20122 \mathrm{~m}$ Temperature Difference (K) (WRF-50S-HLAl-AWDN) 18 UTC

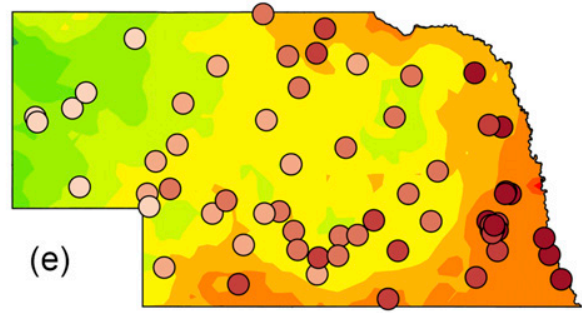

\section{Summer 20122 m Temperature Difference $(K)$ (WRF-Ctrl-AWDN)}

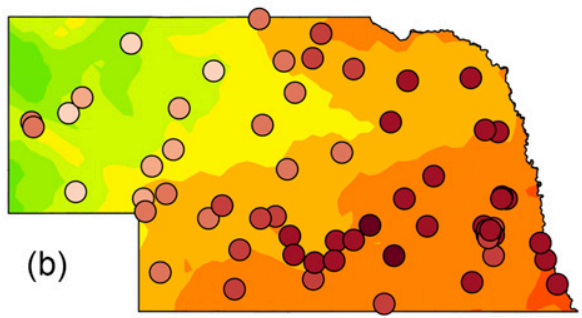

Summer $20122 \mathrm{~m}$ Temperature Difference $(\mathrm{K})$ (WRF-50S-DLAI - AWDN)

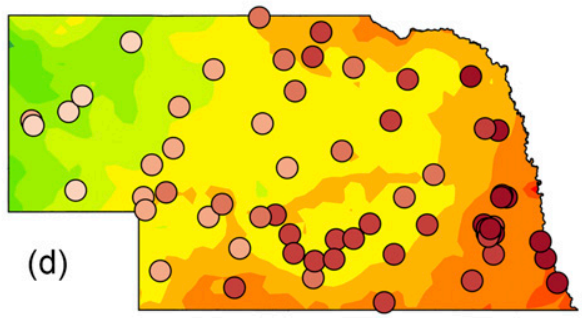

Summer $20122 \mathrm{~m}$ Temperature Difference (K) (WRF-Natural - AWDN) 18 UTC

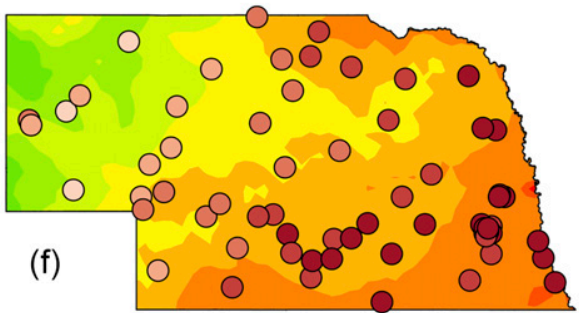

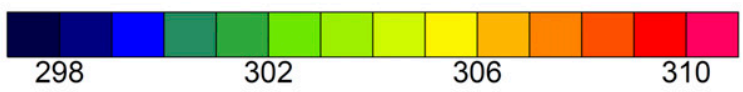

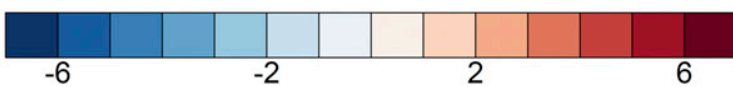

FIG. 8. (a) Land-use classification of AWDN stations, and simulated summer 2012 2-m temperature difference vs AWDN observations averaged at 1800 UTC for (b) WRF-Ctrl, (c) WRF-DS-HLAI, (d) WRF-50S-DLAI, (e) WRF-50S-HLAI, and (f) WRF-Natural overlaid on simulated summer 2012 2-m temperature averaged at 1800 UTC for each respective WRF run.

used in WRF-50S-HLAI (peak of 2.38 vs peak of 4.09, respectively). LAI values for grassland CLM values are actually very similar during the peak of the growing season; default CLM irrigated LAI peaks at 2.55.

\section{d. Impact above the surface}

The effects of irrigation on $T_{2 \mathrm{~m}}$ are readily visible in the previously discussed figures; it is important to examine how far this temperature impact extends vertically. To do this, the temperature field was analyzed at the 925-, 850-, 700-, 500-, 400-, 300-, 200-, 150-, and 100-hPa levels for each run. The highest level at which any definitive pattern was visible was at $850 \mathrm{hPa}$, which is illustrated in Fig. 7 . The simulated 1800 UTC average temperature at $850 \mathrm{hPa}$ $T_{850}$ from WRF-Ctrl is shown in Fig. 7a. Results show the expected pattern of an increase in $T_{850}$ to the west, as elevation increases and $850 \mathrm{hPa}$ becomes closer to the surface (note that the white areas in the Nebraska Panhandle are locations in which the surface pressure is less than $850 \mathrm{hPa}$ ). Similar to impacts on $T_{2 \mathrm{~m}}$, all simulations show a cooling effect at $850 \mathrm{hPa}$ throughout most of Nebraska. WRF-DS-HLAI has the smallest impact on 


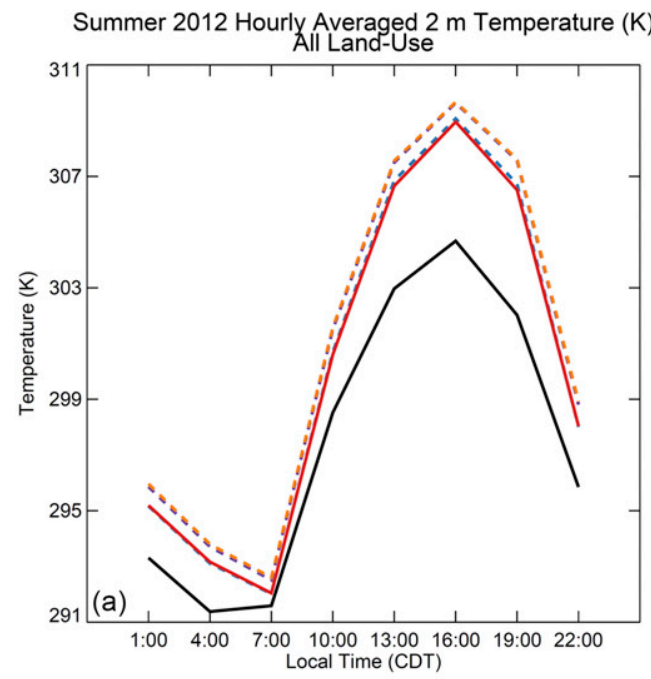

WRF-Ctrl

WRF-50S-DLAI

WRF-DS-HLAI

WRF-50S-HLAI

AWDN
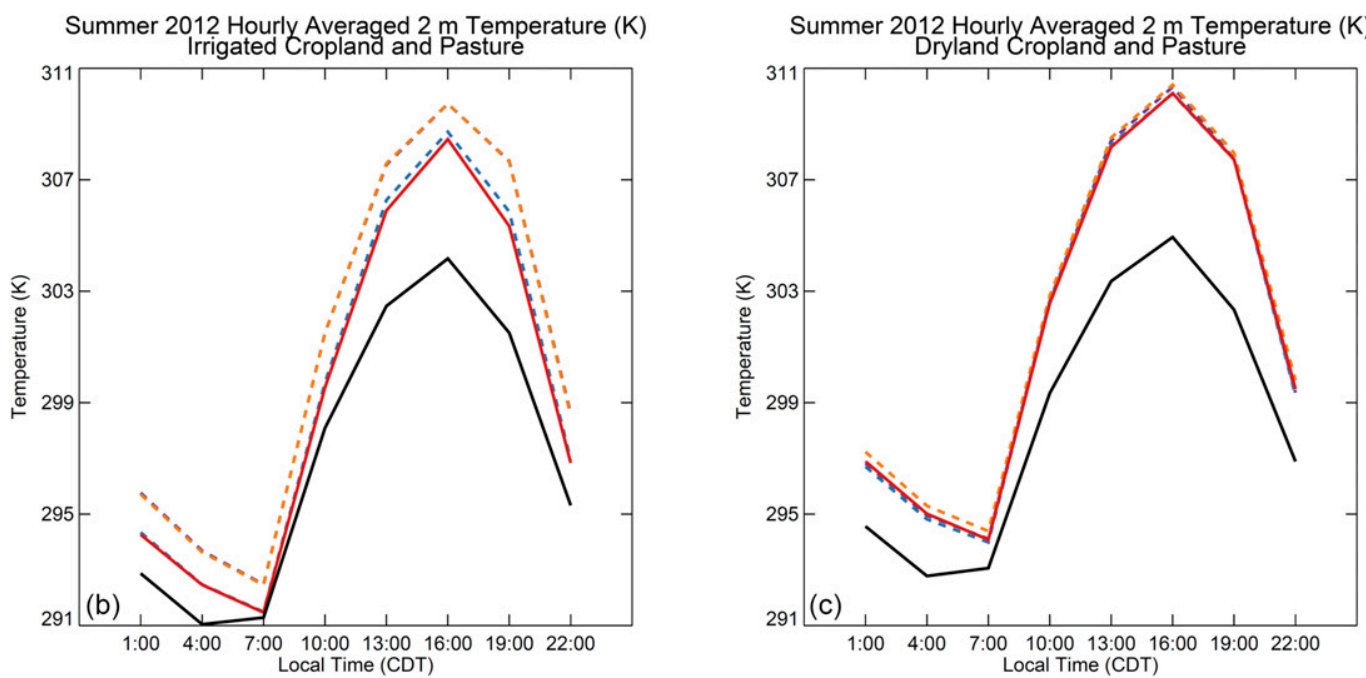

FIG. 9. Hourly averaged 2-m temperature in Nebraska for (a) all land uses, (b) irrigated cropland and pasture, and (c) dryland cropland and pasture for WRF-Ctrl (purple dashed line), WRF-50S-DLAI (blue dashed line), WRFDS-HLAI (orange dashed line), WRF-50S-HLAI (red solid line), and AWDN observations (black solid line).

temperatures, with maximum $T_{850}$ decreases near $0.20 \mathrm{~K}$ (Fig. 7b). WRF-50S-DLAI and WRF-50S-HLAI once again exhibit the largest temperature decreases, with maximum decreases of more than $0.60 \mathrm{~K}$, and WRF-50SHLAI showing a slightly larger area experiencing the maximum decrease (Figs. 7c,d). The WRF-Natural simulation also shows a cooling effect on $T_{850}$, much like it showed a cooling impact on $T_{2 \mathrm{~m}}$, with maximum decreases of $\sim 0.40 \mathrm{~K}$ (Fig. $7 \mathrm{e}$ ). While these temperature impacts are relatively small in magnitude, they are systematic and persistently follow the irrigated areas in the WRF-50S-DLAI and WRF-50S-HLAI simulations. Examination of simulated temperatures at $700 \mathrm{hPa}$ also shows a temperature decrease throughout most of Nebraska, although no obvious pattern is seen with regards to its spatial correlation with the irrigated area; for this reason, it is not shown. Therefore, the vertical extent of irrigation's impacts on temperature likely ends between 850 and $700 \mathrm{hPa}$, which correspond to standard atmosphere heights of 1500 and $3000 \mathrm{~m}$, respectively. This cooling aloft, although small in magnitude, would lead to an increase in convective available potential energy as well as smaller dewpoint depressions, which would in turn favor the presence of clouds.

\section{e. Model evaluation}

In general, incorporating an irrigation parameterization in CLM leads to a decrease of near-surface temperatures over irrigated areas. To determine whether the magnitude of this cooling effect simulated by the model is at least somewhat realistic, simulated $T_{2 \mathrm{~m}}$ is compared with AWDN-observed $T_{2 \mathrm{~m}}$ (Fig. 8). This analysis shows 
TABLE 4. Average simulated $\mathrm{T}_{2 \mathrm{~m}}$ error $(\mathrm{K})$ with respect to AWDN observations.

\begin{tabular}{|c|c|c|c|c|c|c|c|c|c|}
\hline \multirow[b]{2}{*}{ Run name } & \multicolumn{8}{|c|}{ Local (central daylight) time) } & \multirow[b]{2}{*}{ Land use } \\
\hline & 0100 & 0400 & 0700 & 1000 & 1300 & 1600 & 1900 & 2200 & \\
\hline \multirow[t]{3}{*}{ WRF-Ctrl } & 2.55 & 2.33 & 0.92 & 2.99 & 4.53 & 4.96 & 5.55 & 2.96 & All \\
\hline & 2.89 & 2.64 & 1.19 & 3.41 & 5.07 & 5.56 & 6.17 & 3.30 & Irrigated \\
\hline & 2.25 & 2.17 & 1.05 & 3.32 & 5.05 & 5.39 & 5.42 & 2.47 & Dryland \\
\hline \multirow[t]{3}{*}{ WRF-DS-HLAI } & 2.65 & 2.42 & 1.01 & 3.06 & 4.59 & 4.99 & 5.60 & 3.06 & All \\
\hline & 2.84 & 2.59 & 1.17 & 3.41 & 5.12 & 5.56 & 6.15 & 3.22 & Irrigated \\
\hline & 2.67 & 2.52 & 1.33 & 3.50 & 5.15 & 5.47 & 5.63 & 2.91 & Dryland \\
\hline \multirow[t]{3}{*}{ WRF-50S-DLAI } & 1.86 & 1.73 & 0.43 & 2.17 & 3.88 & 4.39 & 4.70 & 2.16 & All \\
\hline & 1.47 & 1.43 & 0.21 & 1.63 & 3.80 & 4.55 & 4.34 & 1.63 & Irrigated \\
\hline & 2.14 & 2.04 & 0.93 & 3.29 & 4.91 & 5.14 & 5.38 & 2.37 & Dryland \\
\hline \multirow[t]{3}{*}{ WRF-50S-HLAI } & 1.88 & 1.78 & 0.45 & 2.08 & 3.69 & 4.27 & 4.49 & 2.19 & All \\
\hline & 1.39 & 1.42 & 0.18 & 1.46 & 3.43 & 4.28 & 3.83 & 1.52 & Irrigated \\
\hline & 2.33 & 2.23 & 1.02 & 3.22 & 4.81 & 5.16 & 5.39 & 2.60 & Dryland \\
\hline
\end{tabular}

that the WRF-Ctrl simulated summer-averaged $T_{2 \mathrm{~m}}$ at 1800 UTC was more than $6 \mathrm{~K}$ warmer than observations in many irrigated locations (Fig. 8b). Modifying LAI in the WRF-DS-HLAI run does not produce much of a change from the WRF-Ctrl run (Fig. 8c). Adding soil moisture reduces the temperature difference by $1-3 \mathrm{~K}$ in irrigated areas (Fig. 8d). Combining the additional soil moisture with modified LAI reduces the temperature difference by another $1 \mathrm{~K}$ in some locations (Fig. 8e). WRF-Natural temperature comparisons with AWDN are included in Fig. $8 \mathrm{f}$ for completeness.

Figure 9 provides another way of illustrating the improvements made in the simulation through the addition of soil moisture and modification of LAI by comparing average observed $T_{2 \mathrm{~m}}$ by AWDN with corresponding WRF grid squares by time of day. It is readily apparent that differences in simulated and observational $T_{2 \mathrm{~m}}$ are greatest during the daytime/ peak heating and that simulations were closer to observations at night. This diurnal temperature difference is due to the model's handling of the coupling between the land surface and the planetary boundary layer (PBL). Because the land surface and PBL interact much more during the daytime (because of surface heating), the WRF PBL scheme is also more active, leading to a greater potential for errors. For each plot, WRF averages were calculated using the WRF grid box that contained an AWDN station. Figure 9a shows averages for all AWDN stations and the corresponding WRF grid boxes. Figure 9b calculates the averages using only AWDN stations that fall within WRF grid boxes classified as irrigated cropland and pasture, and Fig. 9c is similar but for WRF grid boxes that are classified as dryland cropland and pasture. The land-use classification of each station is illustrated in Fig. 8a. Figure 9 illustrates that the greatest improvement is made for irrigated areas, but only a $2-3-\mathrm{K}$ cooling is experienced when using WRF50S-HLAI versus WRF-Ctrl. On average, the irrigated locations containing AWDN observations in the WRF-50S-HLAI simulation are still approximately $4 \mathrm{~K}$ too warm at $2100 \mathrm{UTC}$, the time of maximum $T_{2 \mathrm{~m}}$. Table 4 provides hourly average error for each model run and each land use.

\section{Secondary impacts}

Although temperature is often examined when studying the impacts of irrigation, moist enthalpy can be used to assess impacts of irrigation on the heat content of air (Pielke et al. 2004). Moist enthalpy $H$ is expressed as

$$
H=C_{p} T+L_{v} q
$$

where $C_{p}$ is the specific heat of air at constant pressure, $T$ is the air temperature, $L_{v}$ is the latent heat of vaporization, and $q$ is the specific humidity. Equivalent temperature $T_{E}$ is then calculated using

$$
T_{E}=H / C_{p},
$$

which can be used as a comparison with temperature as in Pielke et al. (2004) and Fall et al. (2010). As for the temperature, the same general pattern of equivalent temperature can be seen in WRF-Ctrl and the various irrigated runs, with the highest values in southeastern Nebraska and decreasing values to the west (Figs. 10a-d). Figures $10 \mathrm{e}-\mathrm{h}$ show equivalent temperature differences between various simulations. In these plots, only areas found to be statistically significant at a $95 \%$ confidence level using a two-tailed, paired $t$ test are plotted. The 50S runs led to increases in equivalent temperature over irrigated areas, with the WRF-50S-HLAI showing the largest increase of $2-3 \mathrm{~K}$ relative to WRF-Ctrl 
Summer 2012 WRF-Ctrl $T_{E}(K)$

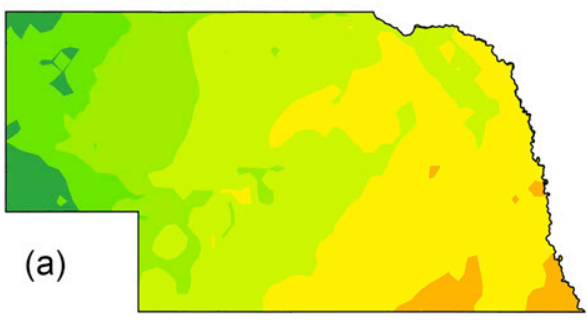

Summer 2012 WRF-50S-DLAI T $\mathrm{E}(\mathrm{K})$ 18 UTC
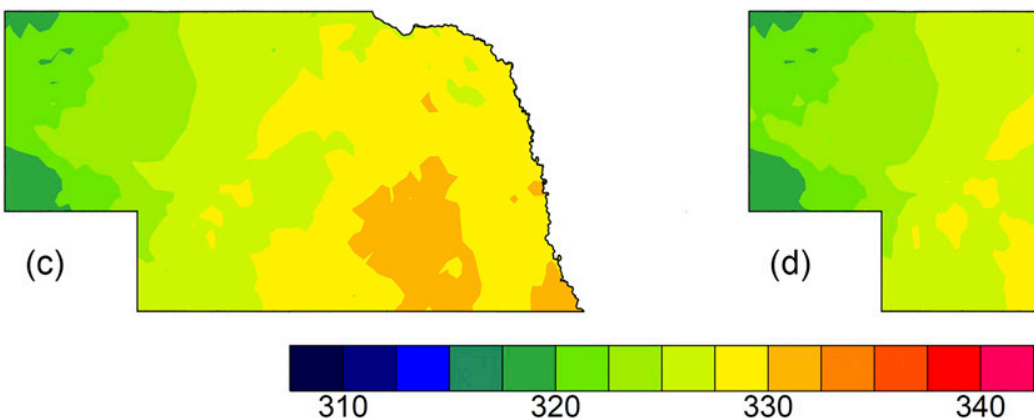

\section{Summer $2012 W_{R F} T_{E}$ Difference $(K)$ (WRF-50S-HLAI-WRF-Ctrl)} 18 UTC

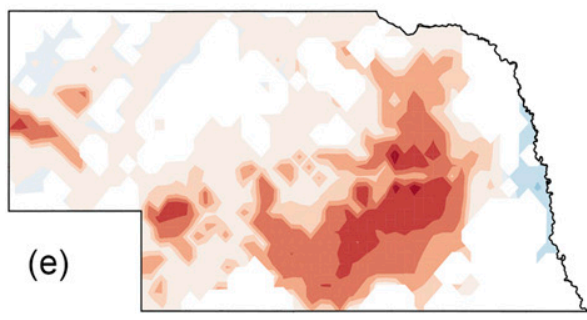

\section{Summer 2012 WRF $T_{E}$ Difference $(K)$ (WRF-50S-HLAl - WRF-50S-DLAl) 18 UTC}

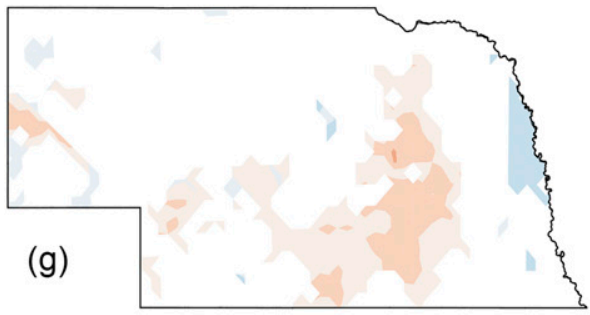

Summer 2012 WRF-DS-HLAI T $\mathrm{E}(\mathrm{K})$

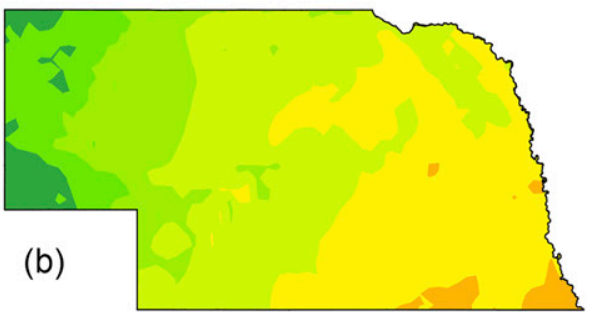

Summer 2012 WRF-50S-HLAI TE
18 UTC

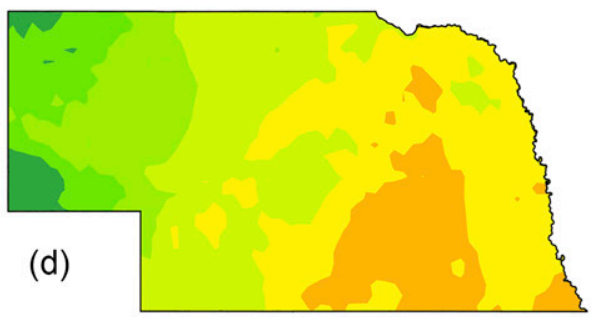

340

\section{Summer 2012 WRF $T_{\text {}}$ Difference $(K)$ (WRF-50S-HLAl - WRF-DS-HLAl) 18 UTC}

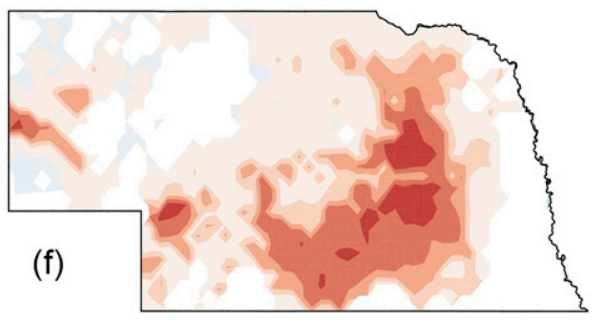

Summer 2012 WRF $T_{E}$ Difference $(K)$ (WRF-DS-HLAl-WRF-Ctrl) 18 UTC
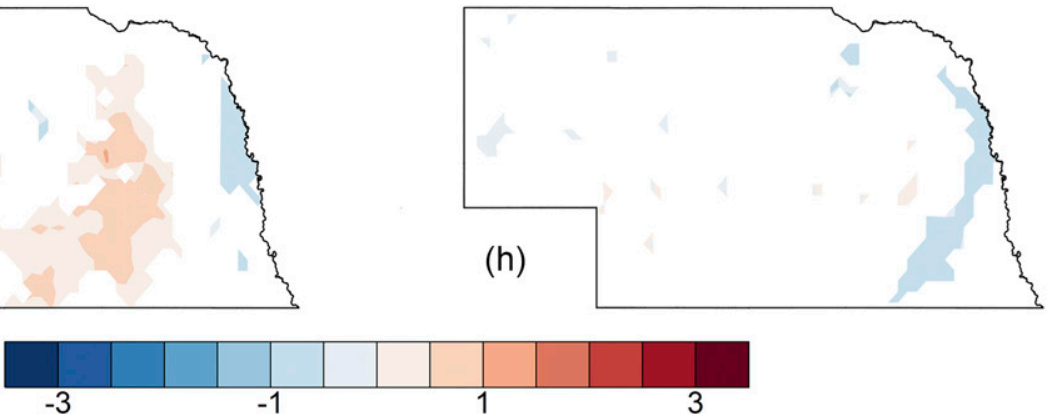

FIG. 10. Simulated summer 2012 surface equivalent temperature averaged at 1800 UTC in Nebraska for (a) WRF-Ctrl, (b) WRF-DS-HLAI, (c) WRF-50S-DLAI, and (d) WRF-50S-HLAI, and simulated summer 2012 surface equivalent temperature difference averaged at 1800 UTC for (e) WRF-50S-HLAI and WRF-Ctrl, (f) WRF-50S-HLAI and WRF-DS-HLAI, (g) WRF-50S-HLAI and WRF-50S-DLAI, and (h) WRF-DS-HLAI and WRF-50S-Ctrl. Areas plotted in (e)-(h) are those found to be statistically significant at a $95 \%$ confidence level using a two-tailed, paired $t$ test. 

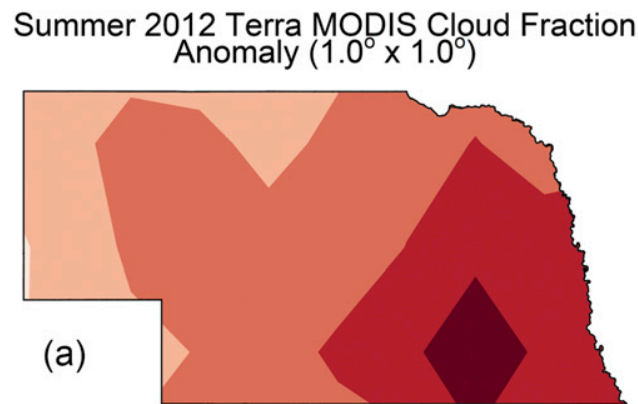

Summer 2012 Terra MODIS Cloud Fraction Anomaly $\left(0.25^{\circ} \times 0.25^{\circ}\right)$

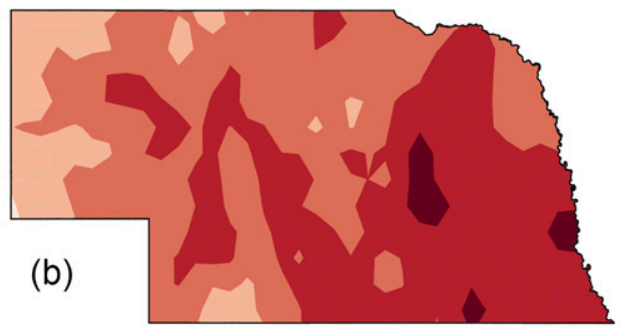

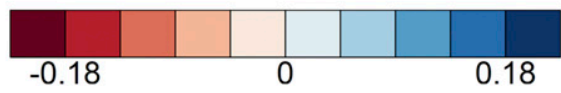

FIG. 11. Summer 2012 cloud-fraction anomaly from (a) MODIS level-3 monthly data and (b) MODIS level-2 granules regridded to $0.25^{\circ} \times 0.25^{\circ}$.

(Fig. 10e). Figures 10f-h illustrate that much of the increase is due to the increased soil moisture as opposed to the modified LAI. Overall, despite the incorporation of irrigation into $\mathrm{WRF}$ leading to a $2-3-\mathrm{K}$ reduction in temperature in irrigated areas, it leads to an increase in moist enthalpy and, therefore, an increase in equivalent temperature of $2-3 \mathrm{~K}$.

One other potential meteorological impact of irrigation is a possible reduction in cloud fraction over irrigated areas. Previous work using monthly MODIS cloudfraction data showed a negative cloud-fraction anomaly in Nebraska in 2012 (a decrease in clouds relative to the average of the previous $10 \mathrm{yr}$ ) as would be expected during a drought, although the largest reduction was over the heavily irrigated area in southeastern Nebraska (Wang et al. 2016; Fig. 11a). A similar pattern was also shown when daily level-2 MODIS cloud-fraction granules with a pixel size of $5 \mathrm{~km}$ were regridded to $0.25^{\circ} \times 0.25^{\circ}$ (Fig. 11b). Although the largest decrease in cloud fraction was not located directly over the area in southeastern Nebraska that is the most densely irrigated, a local minimum in cloud-fraction anomaly (large decrease in cloud fraction) does exist just north of this area, which is also irrigated (although not as heavily). One potential hypothesis for this result is the development of a sea-breeze-like circulation in which air rises over the warmer, nonirrigated areas and subsides over the cooler, irrigated areas, leading to less cloud cover in the irrigated areas. Similar circulations are described by Ookouchi et al. (1984).

One way to test the plausibility of this hypothesis is to examine simulated divergence, because subsidence over irrigated areas would lead to surface divergence. In general, simulation results show surface divergence over irrigated areas and convergence or, in some cases, less divergence over nonirrigated areas (Fig. 12). When additional soil moisture is added in WRF, irrigated areas experience enhanced divergence relative to non-50S simulations, but the modification of LAI leads to different results depending on the presence of added soil moisture. The WRF-Ctrl simulation averaged at 1800 UTC shows no discernible pattern in Nebraska other than a large convergent zone in northwestern Nebraska and a small divergent zone in the panhandle (Fig. 12a). Simply modifying the LAI of WRF-Ctrl leads to very little change throughout Nebraska (Fig. 12b). Figures 12c and $12 \mathrm{~d}$ show that additional soil moisture leads to more surface divergence over irrigated areas. Figures 12e and $12 \mathrm{f}$ show difference plots between WRF-DS-HLAI and WRF-Ctrl and between WRF-50S-HLAI and WRF-Ctrl, respectively. In these plots, only areas found to be statistically significant at a $95 \%$ confidence level using a two-tailed, paired $t$ test are plotted. It is clear that WRF-DSHLAI has very little significant change from WRF-Ctrl. In contrast, WRF-50S-HLAI exhibits several statistically significant areas, including the area of divergence in the Nebraska Panhandle, which is present in WRF-Ctrl, but Fig. 12f illustrates just how much larger the divergence becomes when adding soil moisture and changing LAI. Also present is a relatively large area of increased surface divergence in eastern central Nebraska; this area corresponds very well to the aforementioned local minimum in cloud-fraction anomaly.

Another hypothesis related to wind flow over irrigated and nonirrigated areas is that warmer temperatures over nonirrigated areas will lead to enhanced mixing and, therefore, that wind direction will be closer to that of the wind aloft as momentum is mixed downward. In contrast, cooler temperatures over irrigated areas promote less mixing, and, therefore, the wind direction will be farther away from that of the wind aloft when compared with the wind direction over nonirrigated areas. Depending on the location of irrigated areas relative to nonirrigated areas, this effect could lead to enhanced convergence at the interface of these two 
Summer 2012 WRF-Ctrl Sfc Div. $\left(10^{5} \mathrm{~s}^{-1}\right)$

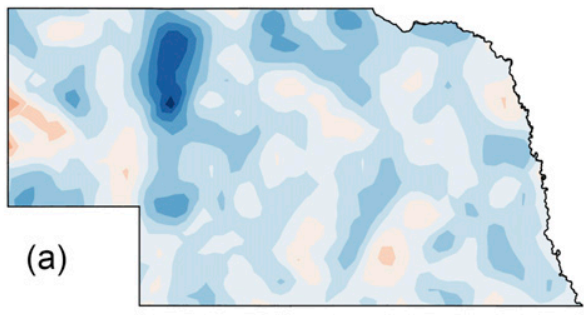

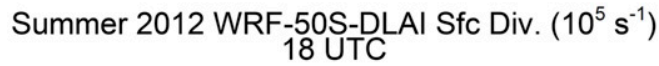

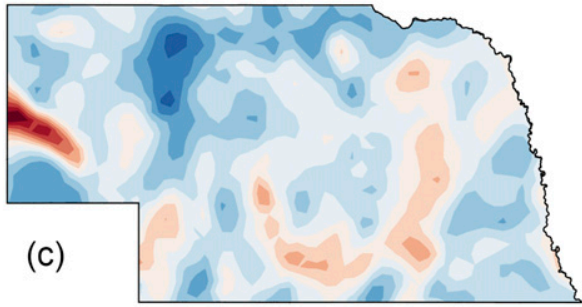

Summer 2012 WRF Sfc Div. Difference $\left(10^{5} \mathrm{~s}^{-1}\right)$ (WRF-DS-HLAl-WRF-Ctrl) 18 UTC

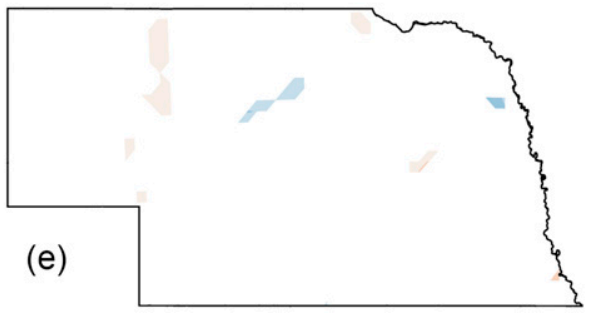

Summer 2012 WRF-DS-HLAI SfC Div. $\left(10^{5} \mathrm{~s}^{-1}\right)$

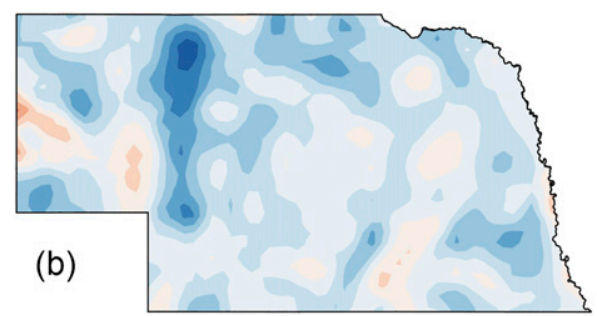

Summer 2012 WRF-50S-HLAI Sfc Div. $\left(10^{5} \mathrm{~s}^{-1}\right)$ 18 UTC

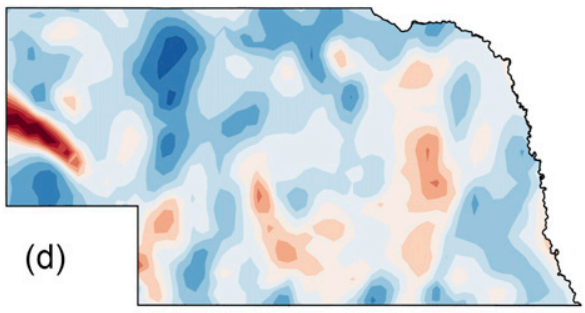

Summer 2012 WRF Sfc Div. Difference $\left(10^{5} \mathrm{~s}^{-1}\right)$ (WRF-50S-HLAl-WRF-Ctrl)

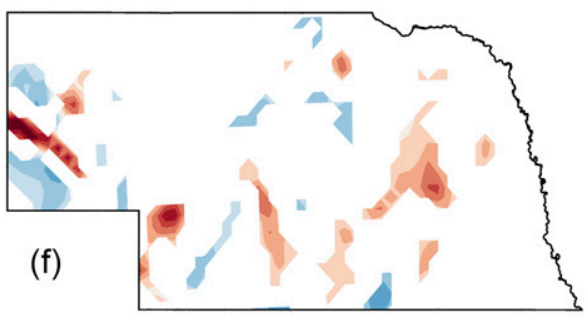

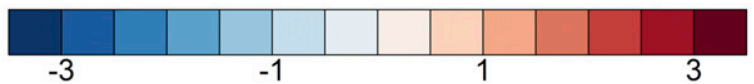

FIG. 12. Simulated summer 2012 surface divergence averaged at 1800 UTC in Nebraska for (a) WRF-Ctrl, (b) WRF-DS-HLAI, (c) WRF-50S-DLAI, and (d) WRF-50S-HLAI, and simulated summer 2012 surface divergence difference vs WRF-Ctrl averaged at 1800 UTC for (e) WRF-DS-HLAI and (f) WRF-50S-HLAI. Areas plotted in (e) and (f) are those found to be statistically significant at a 95\% confidence level using a two-tailed, paired $t$ test.

areas. This hypothesis is illustrated in Fig. 13. A narrow band of increased convergence in southwestern $\mathrm{Ne}$ braska is visible in Fig. 12f. This band is located just to the west of the main area of irrigation in Nebraska, which would support the hypothesis, but is also to the east of another smaller area of irrigation and increased divergence. Therefore, this area could simply be the convergence zone that would have to form between two areas of divergence. A similar area exists in southern central Nebraska, with increased convergence between two areas of irrigation and increased divergence.

Another secondary impact of irrigation that is readily visible in the WRF simulations is a decrease in PBL height $H_{\mathrm{PBL}}$. Figure 14a illustrates the $1800 \mathrm{UTC}$ average $H_{\mathrm{PBL}}$ from the WRF-Ctrl simulation. Overall, $H_{\mathrm{PBL}}$ tends to increase as one moves west throughout Nebraska. Once again, the WRF-DS-HLAI simulation shows very little change relative to the WRF-Ctrl simulation, as shown by the fact that very few statistically significant areas show up (Fig. 14b). Large decreases in $H_{\mathrm{PBL}}$ near $500 \mathrm{~m}$ corresponding well to irrigated areas are simulated by WRF-50SDLAI and WRF-50S-HLAI (Figs. 14c,d). WRF-Natural also shows a statistically significant decrease in $H_{\mathrm{PBL}}$ near $200 \mathrm{~m}$ in the areas converted to grassland (Fig. 14e). None of these results are surprising, because the decreases in $H_{\mathrm{PBL}}$ correspond well to decreases in temperature.

It is also shown that WRF-50S runs lead to an increase in surface pressure over the irrigated areas in Nebraska 


\section{Plan view}
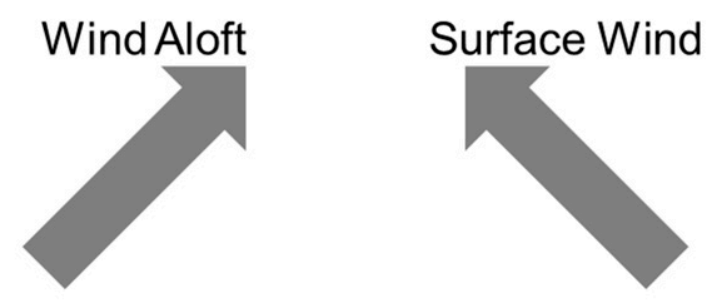

\section{Convergence}

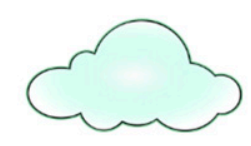

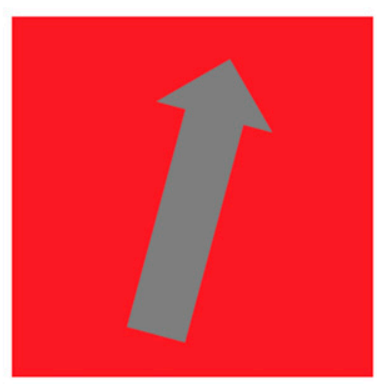

Non-Irrigated

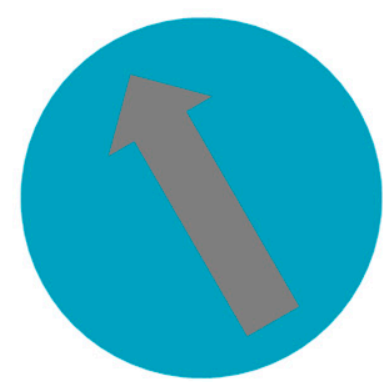

Irrigated
FIG. 13. Plan view of the hypothesis that wind over irrigated areas will have a wind direction that is closer to that of the surface whereas wind over nonirrigated areas will have a wind direction that is closer to that of the winds aloft.

(Fig. 15). The general pattern in surface pressure simulated by WRF-Ctrl shows the expected decrease as one moves west through Nebraska and terrain elevation increases (Fig. 15a). As has been the case for nearly all variables examined thus far, WRF-DS-HLAI simulates almost no statistically significant change relative to WRFCtrl (Fig. 15b). WRF-50S-DLAI, WRF-50S-HLAI, and WRF-Natural simulate statistically significant, although small in magnitude, pressure increases of approximately $0.30,0.40$, and $0.10 \mathrm{hPa}$, respectively (Figs. $15 \mathrm{c}-\mathrm{e}$ ). The center of the higher pressures corresponds very well to the largest decrease in cloud fraction seen in the regridded level-2 MODIS cloud-fraction data in Fig. 11b.

This study also briefly examines the potential impacts of irrigation on precipitation. If the sea-breeze circulation does occur, it should ideally in turn lead to a decrease in precipitation over irrigated areas. Also, if there are enhanced areas of convergence along boundaries between irrigated and nonirrigated areas, these areas (or possibly areas downwind) could receive more precipitation. Previous studies on this subject show contrasting results, with some indicating that an increase in precipitation occurs downwind of irrigated areas
(DeAngelis et al. 2010) whereas others find an increase in precipitation directly over irrigated areas (Harding and Snyder 2012). This study finds no significant pattern changes in precipitation from run to run.

\section{Summary and conclusions}

Both modeling and observational studies show that irrigation can have a significant impact on regional weather and climate. Through model simulations, as well as through both ground-based and satellite-based observations, this study attempted to understand and quantify the effect of irrigation on weather and climate during a time of severe drought in Nebraska. A parameterization scheme for irrigation was added into WRF. Although simple, this scheme has several merits:

1) Irrigation area must be spatially represented accurately. To accomplish this, the MIrAD dataset is merged with the default WRF land-use dataset and compared with registered well data to determine a suitable representation of irrigation land use.

2) Soil moisture must be added to represent the direct effects of irrigation. In this study, soil moisture in irrigated areas is kept at a minimum of $50 \%$ of available water-holding capacity. In comparison with many previous studies that saturate the soil in irrigated areas, this is a conservative approach. Center-pivot irrigation, which is the main type of irrigation used in Nebraska, does not instantaneously saturate the soil in an entire field, and therefore, simulating irrigation by saturating entire WRF grid cells is an inaccurate representation.

3) The physical response of plants to irrigation, such as increased LAI in irrigated areas, must be accounted for in the LSM. While this is technically accounted for in past studies, because most LSMs have a default satellite-derived time series of LAI values for different land uses, no study addresses the issue that these time series are not necessarily applicable in all simulation time periods. For example, during drought, crops that are not irrigated will likely wilt and/or die during the growing season, leading to reduced LAI values in these areas. Because the LAI values are not dynamically simulated, however, these plants remain healthy in model simulations during drought. To address this situation, this study uses simulated 2012 LAI values for irrigated and dryland cropland from the Hybrid-Maize crop model. These values account for the early wilting and death of nonirrigated crops and also give a higher peak LAI value for both irrigated and dryland crops, allowing an examination of the model's sensitivity to these changes. 

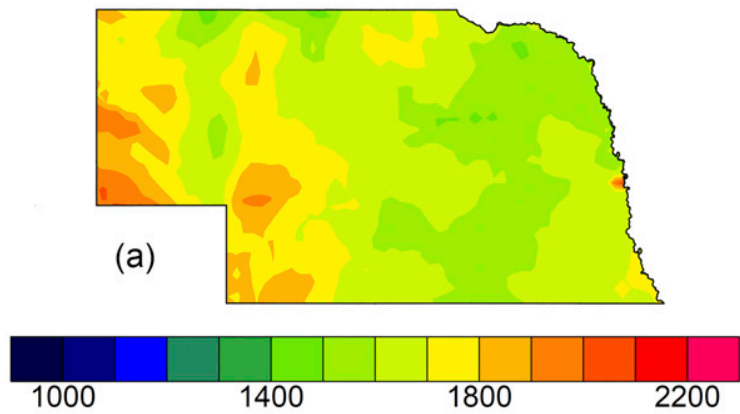

Summer 2012 WRF PBL Height Difference (m) (WRF-DS-HLAl - WRF-Ctrl)

\section{Summer 2012 WRF PBL Height Difference (m)} 18 UTC

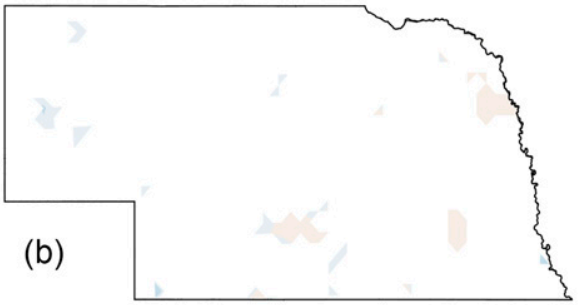

Summer 2012 WRF PBL Height Difference (m) (WRF-50S-HLAl-WRF-Ctrl)
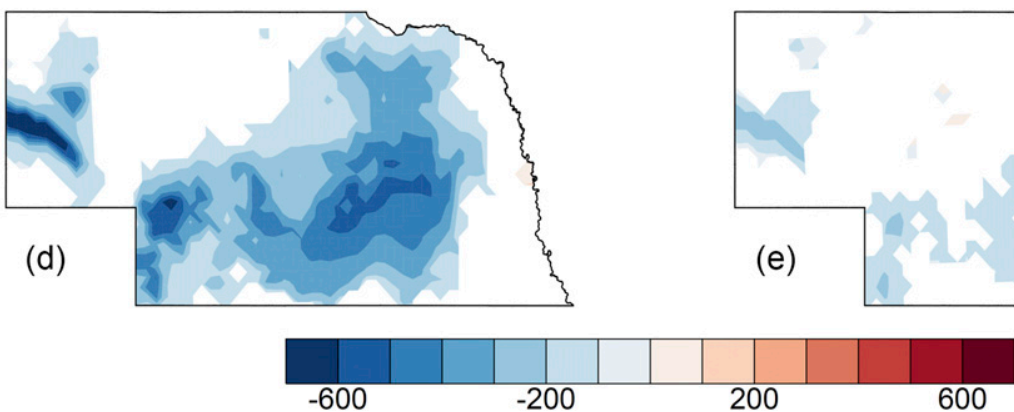

FIG. 14. (a) Simulated summer 2012 PBL height averaged at 1800 UTC for WRF-Ctrl, and simulated summer 2012 PBL height difference vs WRF-Ctrl averaged at 1800 UTC for (b) WRF-DS-HLAI, (c) WRF-50S-DLAI, (d) WRF-50S-HLAI, and (e) WRF-Natural. Areas plotted are those found to be statistically significant at a 95\% confidence level using a two-tailed, paired $t$ test.

This parameterization scheme enabled us to conduct a series of numerical experiments to simulate the model sensitivity to these different aspects of the parameterization. We found that inclusion of all three parameterization aspects led to simulation results that are most consistent with satellite-based and groundbased temperature observations. Simply changing the land-use dataset from the default WRF land use had nearly no impact on simulated temperature. Combining the modified land use with the modified LAI time series also led to very little change in simulated temperatures, with temperature decreases in irrigated areas of at most $0.25 \mathrm{~K}$ in irrigated areas relative to WRF-Ctrl. The modified LAI values also led to an increase in temperatures of a similar magnitude in dryland areas. The introduction of additional soil moisture had a much larger impact on simulated temperatures than did any other aspect of the parameterization scheme, leading to a temperature decrease of $1-2 \mathrm{~K}$ in irrigated areas relative to WRF-Ctrl. Incorporating the modified LAI time series led to an additional $0.5-1-\mathrm{K}$ temperature decrease in these areas.

Several secondary impacts of irrigation were also examined. Moist enthalpy/equivalent temperature 
Summer 2012 WRF-Ctrl Sfc Pressure (hPa)
18 UTC
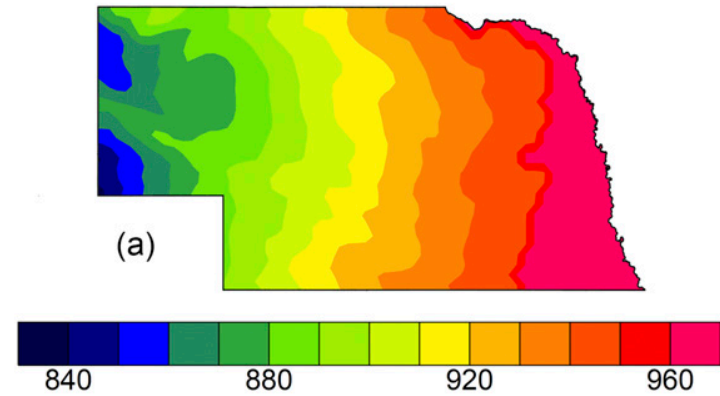

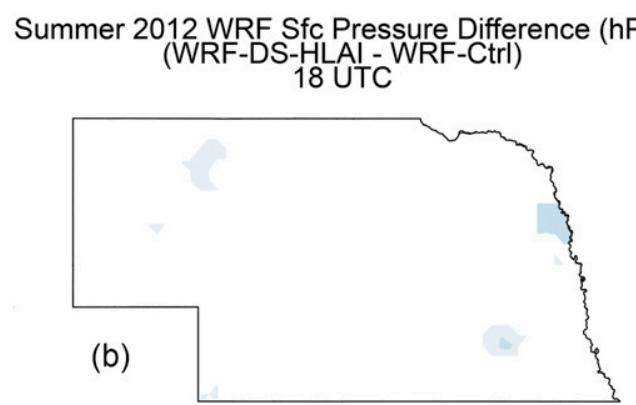

Summer 2012 WRF Sfc Pressure Difference (hPa) (WRF-50S-HLAI-WRF-Ctrl) 18 UTC
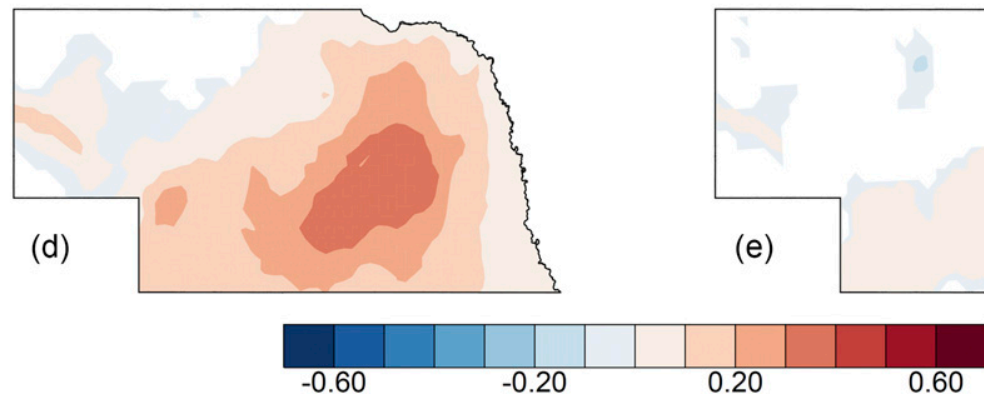

FIG. 15. As in Fig. 14, but for surface pressure and surface pressure difference.
Summer 2012 WRF Sfc Pressure Difference (hPa) (WRF-50S-DLAI - WRF-Ctrl)

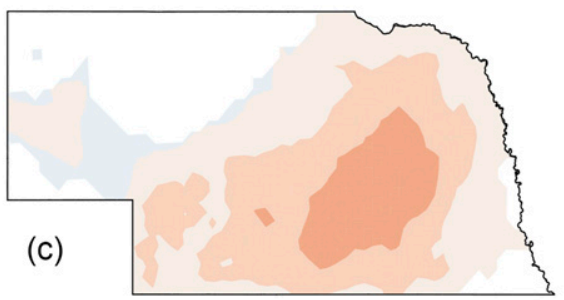

Summer 2012 WRF Sfc Pressure Difference (hPa) (WRF-Natural - WRF-Ctrl)

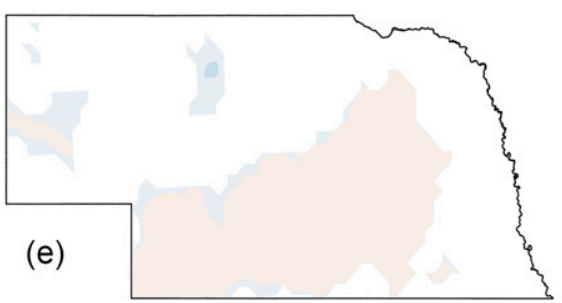

60 was found to increase when adding additional soil moisture, indicating an increase in surface air heat content. This being the case despite a reduction in temperature further emphasizes the significant amount of moisture being added to the air through irrigation. We also found that incorporating irrigation led to increased surface pressure in irrigated areas. Along with this pressure increase was an increase in surface divergence, supporting the hypothesis of a circulation occurring in which subsidence takes place over irrigated areas. A more divergent and anticyclonic pattern is also seen in the main irrigated area in southeastern Nebraska when plotting $10-\mathrm{m}$ wind difference between WRF-50S-HLAI and WRF-Ctrl (not shown). Also, the PBL height over irrigated areas was found to decrease by nearly $500 \mathrm{~m}$.
In addition to the irrigation parameterizations, a final WRF run was conducted in which the irrigated areas in Nebraska were replaced with grasslands. This was to simulate the hypothetical situation that farmers cannot grow crops in these areas because there is no groundwater with which to irrigate. This simulation was warmer than the WRF-50S-HLAI simulation by just over $1 \mathrm{~K}$ in the newly introduced grassland areas. These same areas were also cooler than the corresponding irrigated area in WRF-Ctrl, although by less than $1 \mathrm{~K}$. It is likely that modification of the LAI time series for grasslands would lead to more accurate results, because grasslands were shown via MODIS data to have LAI values between 0 and 1 during the 2012 drought. Overall, this simulation served as another method of examining how humans have had an impact 
on weather and climate, which will continue to be an important issue moving forward.

Acknowledgments. This research is partially supported by the Office of Research and Economic Development at the University of Nebraska and the NASA Applied Science program (Grant NNX15AC28A managed by Dr. John A. Haynes). The Holland Computing Center of the University of Nebraska-Lincoln (UNL) is acknowledged for help in computing. We also thank Professor Prem Paul, the late vice chancellor for Research and Economic Development at UNL, for his support and encouragement to us in conducting this interdisciplinary research work.

\section{REFERENCES}

Adegoke, J. O., R. A. Pielke Sr., J. Eastman, R. Mahmood, and K. G. Hubbard, 2003: Impact of irrigation on midsummer surface fluxes and temperature under dry synoptic conditions: A regional atmospheric model study of the U.S. high plains. Mon. Wea. Rev., 131, 556-564, doi:10.1175/ 1520-0493(2003)131<0556:IOIOMS > 2.0.CO;2.

,$- \ldots$, and A. M. Carleton, 2007: Observational and modeling studies of agriculture-related land use change on planetary boundary layer processes in the central U.S. Agric. For. Meteor., 142, 203-215, doi:10.1016/j.agrformet.2006.07.013.

Bastable, H. G., J. W. Shuttleworth, R. L. G. Dallarosa, G. Fisch, and C. A. Nobre, 1993: Observations of climate, albedo and surface radiation over cleared and undisturbed Amazonian forest. Int. J. Climatol., 13, 783-796, doi:10.1002/ joc.3370130706.

Bonfils, C., and D. Lobell, 2007: Empirical evidence for a recent slowdown in irrigation- induced cooling. Proc. Natl. Acad. Sci. USA, 104, 13 582-13 587, doi:10.1073/pnas.0700144104.

Brown, J. F., and M. S. Pervez, 2014: Merging remote sensing data and national agricultural statistics to model change in irrigated agriculture. Agric. Syst., 127, 28-40, doi:10.1016/ j.agsy.2014.01.004.

- — - and S. Maxwell, 2009: Mapping irrigated lands across the United States using MODIS satellite imagery. Remote Sensing of Global Croplands for Food Security, P. Thenkabail, J. G. Lyon, C. M. Biradar, and H. Turral, Eds., Taylor and Francis, 177-198.

Cook, B. L., M. J. Puma, and N. Y. Krakauer, 2011: Irrigation induced surface cooling in the context of modern and increased greenhouse gas forcing. Climate Dyn., 37, 1587-1600, doi:10.1007/s00382-010-0932-x.

Crook, N. A., 1996: Sensitivity of moist convection forced by boundary layer processes to low-level thermodynamic fields. Mon. Wea. Rev., 124, 1767-1785, doi:10.1175/1520-0493(1996)124<1767: SOMCFB $>2.0 . \mathrm{CO} ; 2$.

DeAngelis, A., F. Dominguez, Y. Fan, A. Robock, M. D. Kustu, and D. Robinson, 2010: Evidence of enhanced precipitation due to irrigation over the Great Plains of the United States. J. Geophys. Res., 115, D15115, doi:10.1029/2010JD013892.

Douglas, E. M., D. Niyogi, S. Frolking, J. B. Yeluripati, R. A. Pielke Sr., N. Niyogi, C. J. Vörösmarty, and U. C. Mohanty, 2006: Changes in moisture and energy fluxes due to agricultural land use and irrigation in the Indian monsoon belt. Geophys. Res. Lett., 33, L14403, doi:10.1029/ 2006 GL026550.

ESRL, 2015: NCEP North American Regional Reanalysis: NARR. NOAA Earth System Research Laboratory. [Available online at http://www.esrl.noaa.gov/psd/data/gridded/data.narr.html.]

Evans, J. P., and B. F. Zaitchik, 2008: Modeling the large-scale water balance impact of different irrigation systems. Water Resour. Res., 44, W08448, doi:10.1029/2007WR006671.

Fall, S., N. Diffenbaugh, D. Niyogi, R. A. Pielke Sr., and G. Rochon, 2010: Temperature and equivalent temperature over the United States (1979-2005). Int. J. Climatol., 30, 20452054, doi:10.1002/joc.2094.

Harding, K. J., and P. K. Snyder, 2012: Modeling the atmospheric response to irrigation in the Great Plains. Part I: General impacts on precipitation and the energy budget. J. Hydrometeor., 13, 1667-1686, doi:10.1175/JHM-D-11-098.1.

Hoerling, M., J. Eischeid, A. Kumar, R. Leung, A. Mariotti, K. Mo, S. Schubert, and R. Seager, 2014: Causes and predictability of the 2012 Great Plains drought. Bull. Amer. Meteor. Soc., 95, 269-282, doi:10.1175/BAMS-D-13-00055.1.

IPCC, 2013: Climate Change 2013: The Physical Science Basis. Cambridge University Press, 1535 pp., doi:10.1017/ CBO9781107415324.

Irmak, S., 2010: Nebraska water and energy flux measurement, modeling, and research network (NEBFLUX). Trans. ASABE, 53, 1097-1115, doi:10.13031/2013.32600.

Jiang, L., E. Ma, and X. Deng, 2014: Impacts of irrigation on the heat fluxes and near-surface temperature in an inland irrigation area of northern China. Energies, 7, 1300-1317, doi:10.3390/en7031300.

Jones, C. A., and J. R. Kiniry, 1986: CERES-Maize: A Simulation Model of Maize Growth and Development. Texas A\&M University Press, $194 \mathrm{pp}$.

King, M. D., S.-C. Tsay, S. E. Platnick, M. Wang, and K.-N. Liou, 1997: Cloud retrieval algorithms for MODIS: Optical thickness, effective particle radius, and thermodynamic phase. NASA GSFC MODIS Algorithm Theoretical Basis Doc. ATBD-MOD-05, version 5, 79 pp. [Available online at https:// eospso.nasa.gov/sites/default/files/atbd/atbd_mod05.pdf.]

- and Coauthors, 2003: Cloud and aerosol properties, precipitable water and profiles of temperature and water vapor from MODIS. IEEE Trans. Geosci. Remote Sens., 41, 442-458, doi:10.1109/TGRS.2002.808226.

Knyazikhin, Y., J. V. Martonchik, R. B. Myneni, D. J. Diner, and S. W. Running, 1998: Synergistic algorithm for estimating vegetation canopy leaf area index and fraction of absorbed photosynthetically active radiation from MODIS and MISR data. J. Geophys. Res., 103, 32 257-32 275, doi:10.1029/ 98JD02462.

Kropff, M. J., and H. H. van Laar, 1993: Modelling Crop-Weed Interactions. CABI, $274 \mathrm{pp}$.

Kueppers, L. M., and M. A. Snyder, 2012: Influence of irrigated agriculture on diurnal surface energy and water fluxes, surface climate, and atmospheric circulation in California. Climate Dyn., 38, 1017-1029, doi:10.1007/s00382-011-1123-0.

- - , and L. C. Sloan, 2007: Irrigation cooling effect: Regional climate forcing by land-use change. Geophys. Res. Lett., 34, L03703, doi:10.1029/2006GL028679.

_ land-use change in the western United States. Global Planet. Change, 60, 250-264, doi:10.1016/j.gloplacha.2007.03.005.

Lawrence, D. M., and Coauthors, 2011: Parameterization improvements and functional and structural advances in version 
4 of the Community Land Model. J. Adv. Model. Earth Sys., 3, M03001, doi:10.1029/2011MS00045.

Lawston, P. M., J. A. Santanello Jr., B. F. Zaitchik, and M. Rodell, 2015: Impact of irrigation methods on land surface model spinup and initialization of WRF forecasts. J. Hydrometeor., 16, 1135-1154, doi:10.1175/JHM-D-14-0203.1.

Lobell, D. B., C. Bonfils, and J. M. Faurès, 2008: The role of irrigation expansion in past and future temperature trends. Earth Interact., 12,1-11, doi:10.1175/2007EI241.1.

Lu, L., J. Jin, and L. M. Kueppers, 2015: Crop growth and irrigation interact to influence surface fluxes in a regional climatecropland model (WRF3.3-CLM4crop). Climate Dyn., 45, 3347-3363, doi:10.1007/s00382-015-2543-z.

Mahmood, R., K. G. Hubbard, and C. Carlson, 2004: Modification of growing-season surface temperature records in the northern Great Plains due to land-use transformation: Verification of modelling results and implication for global climate change. Int. J. Climatol., 24, 311-327, doi:10.1002/joc.992.

—_, and Coauthors, 2014: Land cover changes and their biogeophysical effects on climate. Int. J. Climatol., 34, 929-953, doi:10.1002/joc.3736.

Maupin, M. A., J. F. Kenny, S. S. Hutson, J. K. Lovelace, N. L. Barber, and K. S. Linsey, 2014: Estimated use of water in the United States in 2010. USGS Rep. 1405, 56 pp., doi:10.3133/ cir1405.

Maxwell, S. K., E. C. Wood, and A. Janus, 2008: Comparison of the USGS 2001 NLCD to the 2002 USDA Census of Agriculture for the upper midwest United States. Agric. Ecosyst. Environ., 127, 141-145, doi:10.1016/j.agee.2008.03.012.

Mesinger, F., and Coauthors, 2006: North American Regional Reanalysis. Bull. Amer. Meteor. Soc., 87, 343-360, doi:10.1175/ BAMS-87-3-343.

Myneni, R., 2012: MODIS LAI/FPAR product user's guide. NASA Goddard Space Flight Center Rep., 7 pp. [Available online at https://lpdaac.usgs.gov/sites/default/files/public/ modis/docs/MODIS-LAI-FPAR-User-Guide.pdf.]

NCEI, 2016: Climatological rankings. NOAA/National Centers for Environmental Information. [Available online at http://www. ncdc.noaa.gov/temp-and-precip/climatological-rankings/.]

Oleson, K. W., and Coauthors, 2010: Technical description of version 4.0 of the Community Land Model (CLM). NCAR Tech. Note NCAR/TN-478+STR, 257 pp. [Available online at http://www. cesm.ucar.edu/models/ccsm4.0/clm/CLM4_Tech_Note.pdf.]

Ookouchi, Y., M. Segal, R. C. Kessler, and R. A. Pielke, 1984: Evaluation of soil moisture effects on the generation and modification of mesoscale circulations. Mon. Wea. Rev., 112, 2281-2292, doi:10.1175/1520-0493(1984)112<2281: EOSMEO $>2.0 . \mathrm{CO} ; 2$.

Ozdogan, M., M. Rodell, H. K. Beaudoing, and D. L. Toll, 2010: Simulating the effects of irrigation over the United States in a land surface model based on satellite-derived agricultural data. J. Hydrometeor., 11, 171-184, doi:10.1175/ 2009JHM1116.1.

Pervez, M. S., and J. F. Brown, 2010: Mapping irrigated lands at 250-m scale by merging MODIS data and national agricultural statistics. Remote Sens., 2, 2388-2412, doi:10.3390/ rs2102388.

Pielke, R. A., Sr., 2001: Influence of the spatial distribution of vegetation and soils on the prediction of cumulus convective rainfall. Rev. Geophys., 39, 151-177, doi:10.1029/ 1999RG000072.

_ irrigated land. Natl. Wea. Dig., 14 (2), 16-17.
— C. Davey, and J. Morgan, 2004: Assessing "global warming" with surface heat content. Eos, Trans. Amer. Geophys. Union, 85, 210-211, doi:10.1029/2004EO210004.

— J. Adegoke, A. Beltrán-Przekurat, C. A. Hiemstra, J. Lin, U. S. Nair, D. Niyogi, and T. E. Nobis, 2007: An overview of regional land-use and land-cover impacts on rainfall. Tellus, 59B, 587-601, doi:10.1111/j.1600-0889.2007.00251.x.

Puma, M. J., and B. I. Cook, 2010: Effects of irrigation on global climate during the 20th century. J. Geophys. Res., 115, D16120, doi:10.1029/2010JD014122.

Qian, Y., M. Huang, B. Yang, and L. K. Berg, 2013: A modeling study of irrigation effects on surface fluxes and land-air-cloud interactions in the southern Great Plains. J. Hydrometeor., 14, 700-721, doi:10.1175/JHM-D-12-0134.1.

Raddatz, R. L., 2007: Evidence for the influence of agriculture on weather and climate through the transformation and management of vegetation: Illustrated by examples from the $\mathrm{Ca}$ nadian prairies. Agric. For. Meteor., 142, 186-202, doi:10.1016/ j.agrformet.2006.08.022.

Sacks, W. J., B. I. Cook, N. Buenning, S. Levis, and J. H. Helkowski, 2009: Effects of global irrigation on the nearsurface climate. Climate Dyn., 33, 159-175, doi:10.1007/ s00382-008-0445-Z.

Saeed, F., S. Hagemann, and D. Jacob, 2009: Impact of irrigation on the South Asian summer monsoon. Geophys. Res. Lett., 36, L20711, doi:10.1029/2009GL040625.

Segal, M., R. Avissar, M. C. McCumber, and R. A. Pielke, 1988: Evaluation of vegetation effects on the generation and modification of mesoscale circulations. J. Atmos. Sci., 45, 2268-2292, doi:10.1175/1520-0469(1988)045<2268: EOVEOT $>2.0$.CO;2.

Sellers, W. D., 1965: Physical Climatology. University of Chicago Press, $272 \mathrm{pp}$.

Siebert, S., P. Döll, J. Hoogeveen, J. M. Faures, K. Frenken, and S. Feick, 2005: Development and validation of the global map of irrigation areas. Hydrol. Earth Syst. Sci., 9, 535-547, doi:10.5194/hess-9-535-2005.

— J. Burke, J. M. Faures, K. Frenken, J. Hoogeveen, P. Döll, and F. T. Portmann, 2010: Groundwater use for irrigation-A global inventory. Hydrol. Earth Syst. Sci., 14, 1863-1880, doi:10.5194/hess-14-1863-2010.

Skaggs, K. E., and S. Irmak, 2012: Long-term trends in air temperature distribution and extremes, growing degree-days, and spring and fall frosts for climate impact assessments on agricultural practices in Nebraska. J. Appl. Meteor. Climatol., 51, 2060-2073, doi:10.1175/JAMC-D-11-0146.1.

Skamarock, W. C., and Coauthors, 2008: A description of the Advanced Research WRF version 3. NCAR Tech. Note NCAR/TN-475+STR, 113 pp., doi:10.5065/D68S4MVH.

USDA, 2004: 2002 Census of Agriculture. U.S. Department of Agriculture Farm and Ranch Irrigation Survey (2003), Vol. 3, Special Studies, Part 1, Rep. AC-02-SS-1, 216 pp. [Available online at https://www.agcensus.usda.gov/Publications/2002/ FRIS/fris03.pdf.]

2014: 2012 Census of Agriculture. U.S. Department of Agriculture Farm and Ranch Irrigation Survey (2013), Vol. 3, Special Studies, Part 1, Rep. AC-12-SS-1, 266 pp. [Available online at https://www.agcensus.usda.gov/Publications/ 2012/Online_Resources/Farm_and_Ranch_Irrigation_Survey/ fris13.pdf.]

USGS, 2016: Global land cover characteristics data base version 2.0. U.S. Geological Survey. [Available online at https://lta.cr. usgs.gov/glcc/globdoc2_0.] 
Wan, Z., 1999: MODIS land-surface temperature algorithm theoretical basis document (LST ATBD), version 3.3. University of California, Santa Barbara, Institute for Computational Earth System Science Tech. Rep., 75 pp. [Available online at http://modis.gsfc.nasa.gov/data/atbd/atbd_mod11.pdf.]

2009: Collection-5 MODIS land surface temperature products users' guide. University of California, Santa Barbara, Institute for Computational Earth System Science Tech. Rep., 30 pp. [Available online at http://www.icess.ucsb.edu/modis/ LstUsrGuide/MODIS_LST_products_Users_guide_C5.pdf.]

Wang, J., and Coauthors, 2016: A multi-sensor view of the 2012 central plains drought from space. Front. Environ. Sci., 4, doi:10.3389/fenvs.2016.00045.
Wardlow, B., and K. Callahan, 2014: A multi-scale accuracy assessment of the MODIS irrigated agriculture data-set (MIrAD) for the state of Nebraska, USA. GISci. Remote Sens., 51, 575-592, doi:10.1080/15481603.2014.952546.

Yang, H. S., A. Dobermann, J. L. Lindquist, D. T. Walters, T. J. Arkebauer, and K. G. Cassman, 2004: Hybrid-maize-A maize simulation model that combines two crop modeling approaches. Field Crops Res., 87, 131-154, doi:10.1016/ j.fcr.2003.10.003.

Zaitchik, B. F., J. Evans, and R. B. Smith, 2005: MODIS-derived boundary conditions for a mesoscale climate model: Application to irrigated agriculture in the Euphrates basin. Mon. Wea. Rev., 133, 1727-1743, doi:10.1175/MWR2947.1. 